\title{
3 Research Soure \\ Identification of IFITM1 with prognostic value in pancreatic cancer using network module-based analysis
}

\section{Lingyun Wu}

Zhejiang University School of Medicine First Affiliated Hospital

\section{Xinli Zhu}

Zhejiang University School of Medicine First Affiliated Hospital

\section{Mengmeng Tang}

Zhejiang University School of Medicine First Affiliated Hospital

\section{Lihong Wang}

Zhejiang University School of Medicine First Affiliated Hospital

\section{Chiyuan Ma}

Zhejiang University School of Medicine Second Affiliated Hospital

\section{Tingbo Liang}

Zhejiang University School of Medicine First Affiliated Hospital

\section{Senxiang Yan ( $\nabla$ yansenxiang@zju.edu.cn )}

Department of Radiation Oncology, the First Affiliated Hospital, College of Medicine, Zhejiang University

\section{Research}

Keywords: Pancreatic cancer, Interferon-induced transmembrane 1(IFITM1), Functional interaction network, Prognostic biomarker

Posted Date: July 28th, 2020

DOI: https://doi.org/10.21203/rs.3.rs-45691/v1

License: (c) (1) This work is licensed under a Creative Commons Attribution 4.0 International License. Read Full License 


\section{Abstract}

Background: Despite improvements reported in diagnosis and treatments in recent decades, pancreatic cancer still characterized with poor prognosis and low survival rate among solid tumors. Intensive interests have grown in exploring novel predictive biomarkers, aiming to enhance the efficiency in early detection and treatment prognosis.

Methods: In this study, we identified the differentially expressed genes (DEGs) in pancreatic cancer through analyzed five gene expression profiles, and established the functional modules according to the functional interaction $(\mathrm{FI})$ network between DEGs.

Results: Significant upregulation of the selected DEG, IFITM1, was evaluated in several bioinformatics online tools and verified with immunohistochemistry staining from 90 pancreatic cancer patients' samples. Prognostic data showed that high expression of IFITM1 associated with poor survival and multivariate Cox regression analysis showed that IFITM1 was one of independent prognostic factor for the overall survival. Meanwhile, significant correlations of the expression of IFITM1 and the infiltration of immune cells were found by TIMER. Furthermore, higher level of IFITM1 was assessed in pancreatic cancer cell lines compared to normal human pancreatic duct epithelial cell and silencing IFITM1 in tumor cells remarkedly inhibited the cancer tumorigenicity.

Conclusion: Collectively, our findings suggested that IFITM1 might have promising clinical utility for pancreatic cancer.

\section{Background}

Pancreatic cancer is expected to be the second leading cause of cancer related deaths in developed countries by 2030 , as characterized with highly invasive and metastatic as well as extremely resistant to chemo-radio-therapy[1]. Despite of some efforts made on adjuvant therapeutics recent years, the clinical mortality ratio remains elevated to date[2]. 5 -year survival rate was reported less than $10 \%$ with an estimated 432,242 deaths occurring worldwide in 2018[3]. Because of this poor prognosis, better identification of clinical biomarkers useful for making therapeutic decisions and developing targets for innovative drugs is urgently needed in this complex and heterogeneous mutational landscape.

The human interferon (IFN)-induced transmembrane protein 1 (IFITM1), also named Leu13 or CD225, is a 17-kDa cell-surface membrane protein in the IFN-stimulated genes (ISGs) protein family along with IFITM2 and IFITM3. Since it was first discovered in neuroblastoma cells in 1984, it has been identified participating in various biological processes including cell proliferation and adhesion, and being important in immunity and antiviral activities[4,5]. Particularly, increasing studies have confirmed that IFITM1 is overexpressed in numerous human cancers during the last decade, such as lung, gastric, colorectal and ovarian cancers[6-9]. Furthermore, positive IFITM1 expression was illustrated in correlations with poorer prognosis in diverse tumors[10, 11]. Hence, it is very likely that IFITM1 may also 
hold hitherto undiscovered value in pancreatic cancer and might be further associated with prognosis of pancreatic cancer patients.

In this study, we investigated gene expression profiles from Gene Expression Omnibus (GEO) repository to screen out common DEGs between pancreatic cancer and normal pancreas tissue, and analyzed them through establishing a protein functional interaction (FI) network. Functional network-based modules were constructed and biological pathways were analyzed afterward. It was confirmed that IFITM1 playing a vital role in pancreatic cancer by 90 pancreas cancer patients with clinical and pathological characteristics and survival time as well as was verified through several bioinformatics online tools. Our study suggested that IFITM1 may have promising clinical utility for prognostic stratification, and combining IFITM1 expression profiles systematically with patients' clinical characteristics is promising to be effective for developing treatment.

\section{Materials And Methods}

\section{Rearch tools}

(1) BRB-Array Tools (version 4.6.0; http://linus.nci.nih.gov/BRB-ArrayTools.html) were used to analysis the DEGs[12]; (2) the Cytoscape software (version 3.7.1; http://www.cytoscape.org) was applied to construct FI network and the network-based functional modules; (3) the FunRich (version 3.1.3; funrich.org) was used to construct biological pathways[13]; (4) the Omicshare online database (https://www. Omicshare.com/), a commercial database based on the Database for Annotation, Visualization and Integrated Discovery (DAVID), was used for the visual analysis of Gene Ontology (GO) and Kyoto Encyclopedia of Genes and Genomes (KEGG) were used for enrichment analysis[14]; (5) the MultiExperiment Viewer (MeV) application (version 4.9.0; http://www.tm4.org/) was used to generate the heat map; (6) some bioinformatics online tools such as the Oncomine database (https://www.oncomine.org/), the Human Protein Atlas (https://www.proteinatlas.org/), the interactive web application Gene Expression Profiling Interactive Analysis (GEPIA) (www.gepia.cancer-pku.cn) and the TIMER database (https://cistrome.shinyapps.io/timer/). A detailed flowchart of identifying the targeted genes associated with pancreatic cancer is shown (Fig. 1).

\section{Patient samples preparation}

A total of 90 human pancreatic cancer specimens were collected, 60 of which with paired non-malignant tissue, between 2004 and 2008 at Taizhou People's Hospital of China for the tissue microarray detection(TMA). All the specimens were stored at the Biobank Center of National Engineering Center for Biochips at Alenabio and Shanghai Outdo Biotech Company, China. All the patients received no preoperative anticancer treatment or post-operative adjuvant chemo-radio-therapy. Histological differentiation grade and disease stages were classified according to the American Joint Committee on Cancer (AJCC) TNM Classification (7th edition). The follow-up time was recorded from the date of the 
surgery to the date of death or last visit to the clinic. The use of pancreatic cancer samples and clinical data were reviewed and approved by the Ethical Committees of the National Engineering Center for Biochips at Shanghai along with the Taizhou People's Hospitals. Informed consent was written in accordance with the Declaration of Helsinki from all participants.

\section{Microarray data}

To investigate biologic characteristics of genes differently expressed between pancreatic cancer and normal pancreas tissue, five datasets retrieved from National Center for Biotechnology Information (NCBI)-GEO (http://www.ncbi.nlm. nih.gov/geo/) were obtained for the analysis, including GSE101448 (18 with pancreatic tumor and 13 non-tumor pancreatic tissue samples), GSE62165 (118 pancreatic tumor samples and 13 control samples), GSE62452 (69 pancreatic tumor and adjacent non-tumor tissues), GSE41372 (matched pancreatic ductal adenocarcinoma samples from 15 patients ) and GSE28735 (45 matching pairs of pancreatic tumor and adjacent non-tumor tissues). NCBI-GEO is a public repository containing an initial database of 1,325 biologically defined gene profiles, and was developed to help analysis and interpretation of the long lists of genes produced from microarray-based experiments. Details of the series data are listed in Table I.

\section{Initial identification of DEGs}

As microarray batch effects appear to be the major contributions to the differential expression, SangerBox online tool (http://sangerbox.com/) was used to eliminate them before taken into account[15]. Next, data were imported into BRB-Array Tools to identify the DEGs between pancreatic tumor and normal pancreas tissues. The affymetrix platform was applied for dataset and gene annotation. The probes were filtered when some gene expression data was missing. The Bioinformatics \& Evolutionary Genomics webtool (http://bioinformatics.psb.ugent.be/webtools/Venn/) was used to depicted graphically in the form of Venn to detect the commonly DEGs among the five datasets.

\section{Establishment of FI network}

The Reactome pathway database (version 7.2.0; http://www.reactome.org) was applied to analyze the pathway enrichment for the sets of genes, investigate the functional relationships of the genes and visualize the outcomes with diagrams that can be manually generated[16]. Over $60 \%$ human proteins were covered to help construct the Reactome FI network. The pairwise interaction information was uploaded into Cytoscape software to establish the FI network[17]. A false discovery rate $(F D R)<0.05$ was accepted as the cut-off criterion.

\section{Construction of the FI network-based functional modules}


To construct the FI network-based module analysis, the Microarray Data Analysis bioinformatics tool installed in the ReactomeFIViz was applied[18]. After uploaded the txt file containing gene expression data, correlations between genes in the Fl-network were analyzed. The Markov cluster algorithm (MCL) was used to achieve the functional modules with a selected module size. In order to supervise the size of the modules, we inputted 5.0 for the inflation coefficient[19]. MCL modules in size of three or more was applied as well as the average Pearson correlation coefficient definition $\geq 0.25$. Six different colors were used to label the nodes in six different network modules. Module size $\geq 7$ and FDG $<0.05$ were used as cutoffs for the KEGG pathway and GO term enrichment analysis of the modules in a separate manner

\section{Preliminary validation of the selected gene}

The Human Protein Atlas (www.proteinatlas.org) presented an expression map of human protein across 20 cancer types and 44 normal human tissues. It measured the RNA level as well as used antibody profiling to precisely localize the corresponding proteins[20]. With the Human Protein Atlas (www.proteinatlas.org), we detected the IFITM1 protein expression in both pancreatic cancer and normal pancreas tissues. Oncomine microarray database (www.oncomine.org) was a cancer microarray database as well as an online data-mining platform which contained 65 gene expression datasets comprising nearly 48 million gene expression measurements form over 4700 microarray experiments[21]. With the Oncomine online tool we explore the expression of IFITM1 in pancreatic cancer and normal pancreas tissues across eight different datasets.

\section{Validation of IFITM1 with the Cancer Genome Atlas (TCGA)}

GEPIA is an online server, containing more than 8,000 normal and 9,000 tumor samples, providing interactive and customizable functions based on TCGA and Genotype-Tissue Expression (GTEx) database[22]. Boxplot with jitter was applied to compare the expression level of IFITM1 mRNA in pancreas cancer and paired normal pancreas tissue. To validate the expression of IFITM1 correlates with pancreatic cancer patients' survivals and pathological stages, it was searched into the database to obtain Kaplan-Meier survival curves and violin plots. The requested mRNA expressions above or below the median were classified the patients into both high and low expression groups. The log rank $P$ value and hazard ratio (HR) with 95\% confidence intervals were calculated and displayed on the website. A $P$-value $<0.05$ was considered statistically significant.

\section{Immunohistochemical (IHC) staining}

To analyze IFITM1 expression by IHC staining experiment, 90 pancreatic cancer patients were included in the TMA analysis. Sample slides were dried for adherence, deparaffinized in xylene decreasing ethanol concentrations. Tissue sections were marked and incubated with rabbit anti-IFITM1 diluted 1:1,500 (ab224063, Abcam, Cambridge, United Kingdom) at $4^{\circ} \mathrm{C}$ overnight. The percentage of the IHC staining 
and the staining intensity were assessed and recorded by two pathologists from the department of pathology, who were both blinded to the patients' features. The H-scores ranged from 0 to 100 , with 100 represented $100 \%$ of regions with strong intensity. The $\mathrm{H}$-scores were dichotomized by the cutoff, the median value, for the statistical analysis.

\section{Cell lines culture and short hairpin RNA (shRNA) lentiviral transduction}

Three human pancreatic cancer cell lines, PanC-1, BxPc-3, SW1990, and one normal pancreatic cell line, HPDE6-C7, were used in the study. The panC-1 and BxPc-3 cells were purchased from the Cell Bank of Shanghai Institute of Biochemistry and Cell Biology ( $\mathrm{SH}, \mathrm{China})$, and the others were purchased from the American Type Culture Collection (ATCC, VA, United States). The panC-1 and HPDE6-C7 cells were cultured in DMEM (Gibco, NY, United States) and the BxPc-3 and SW1990 cells were cultured in RPMI 1640 (Gibco, NY, United States) with both cultures supplemented with 10\% FBS (Gibco, NY, United States) and $100 \mathrm{U}$ penicillin/streptomycin (Gibco, NY, United States) in a humid atmosphere containing $5 \% \mathrm{CO}_{2}$ at $37^{\circ} \mathrm{C}$. Short-tandem repeat (STR) profiles were authenticated to ensure the quality of the cell lines. All of the cells were passaged by standard cell culture techniques.

Two lentivirus-derived shRNAs against IFITM1 were designed by Biolink Biotechnology Co. Ltd (SH, China) to silence IFITM1 mRNA expression (the targeted sequences as follows: IFITM1 shRNA-1, 5'CCTCATGACCATTGGATTCAT-3'; IFITM1 shRNA-2, 5'- CCTGTTCAACACCCTCTTCTT-3'. The procedure of transducing pancreatic cancer lines with shRNA lentiviral transduction was described in detail previously [23].

\section{Cell viability assay}

Cells in logarithmic growth phase were seeded in 96-well Falcon Petri dishes (3000 cells/well) the day before assays were performed. Cell viability was assessed with a cell counting kit (Dojindo, Kumamoto, Japan) based on sensitive colorimetric assays with the absorbance measured at $450 \mathrm{~nm}$ (OD $450 \mathrm{~nm}$ ), according to the manufacturer's instructions. The results were confirmed with three independent experiments.

\section{Quantitative real-time polymerase chain reaction(qRT-PCR) analysis}

To extract total RNA, cells were lysed with TRIzol reagent (Invitrogen Corporation, CA, USA) and reversed into complementary DNA (cDNA) with the QuantiTect Reverse Transcription kit (TAKARA, DL, China). The sequences of the designed primers used for the qRT-PCR experiments were as follows: IFITM1 forward, 5'AGCCAGAAGATGCACAAGGA-3' and reverse, 5'-GATCACGGTGGACCTTGGAA-3'; GAPDH forward, 5'- 
GAAGGTCGGTGTGAACGGATTTG-3' and reverse, 5'- CATGTAGACCATGTAGTTGAGGTCA-3' (Sangon, SH, China).

\section{Western blot analysis}

RIPA (Invitrogen Corporation, CA, United States) added with protease and phosphatase inhibitors were used to gained total protein samples. Proteins were separated by the SDS-PAGE gel (Bio-Rad, CA, United States) and transferred to the PVDF membrane (Sigma Chemical Corporation, MO, United States). Membranes were blocked for one hour and then incubated overnight with primary antibodies against IFITM1 and $\beta$-actin (Abcam, Cambridge, United Kingdom), followed by the HRP-linked secondary antibodies. SuperSignal West Femto Maximum Sensitivity Substrate (Thermo Fisher, Waltham, United States) was used to detect the probed proteins.

\section{Wound healing assay}

Cells were seeded in 48-well Falcon Petri dishes. Once reached $80-90 \%$ confluence, a $200 \mu \mathrm{L}$ sterile plastic pipette tip was used to made a single wound by gently scratching in every well. Cell debris were removed with phosphate buffered saline and refreshed with serum-free medium immediately. Cells that extended the borders of the wound were taken photos and quantified in three randomly selected regions per well.

\section{Colony formation assay}

Cells in logarithmic growth phase were seeded in 6-well Falcon Petri dishes (500 cells/well) and incubated for 7-14 days. The medium was refreshed every three days. The colonies were fixed with $70 \%$ ethanol and stained with crystal violet $(0.5 \% \mathrm{w} / \mathrm{v})$. Cell colonies containing at least 50 cells were taken photos and quantified. Results were presented as means \pm SD of three independent experiments.

\section{Statistical analysis}

Statistical analyses were performed using SPSS 23.0 (SPSS Inc.; Chicago, IL, United States) and Prism 8 (GraphPad Software, San Diego, CA, United States). Correlations between protein expression and clinicopathologic features in pancreatic cancer patients were analyzed by the $\chi 2$ test. Overall survival was evaluated using the Kaplan-Meier method and the log-rank test. A Cox proportional hazards regression model was used to assess the univariate and multivariate analyses. The Enter method was used to select the independent variables in the multivariate analysis.

\section{Results}




\section{Screening of DEGs}

Five datasets from GEO containing gene expression profiles of pancreatic cancer as well as normal pancreas samples were downloaded for microarray analysis. Random variance mode method along with the paired $t$-test was applied for the differential expression calculation. Considering the criteria of llog2 (Fold change) $\mid>1$ adjusted $P$ value $<0.05,483$ DEGs were obtained (Fig. 2A). Of those, 231 DEGs were identified up-regulated and 252 down-regulated (Table S1).

\section{Establishment of pancreatic cancer-related FI network}

Fls data derived from the Human Protein Reference Database[24], BioGrid[25], I2D[26], IntACT[27], MINT[28], the Database of Interacting Proteins[29] as well as multiple high-throughput assays[30]. We established the FI network through mapping the pancreatic cancer-related DEGs to the Fls data. 245 isolated nodes and 227 in eight clusters were identified with an effective mean degree of 2.20 (Fig. 2B). The connectivity of a node represents the number of its neighbors and the neighborhood connectivity represents the average connectivity of all neighbors of the selected node. Under the criteria of neighborhood connectivity $\geq 20$ and the shortest path length $\geq 3.5$ for nonsingle modules, eight genes (EDIL3, RSAD2, AHR, GBP2, IFITM1, AOX1, KIF11, and CEP170) among all the nodes in the FI network were filtered out (Table S2).

\section{Functions analysis of the FI network}

To gain insights into the role of the putative targets involved in various biological processes and molecular functions, preliminary GO function and KEGG pathways analysis were performed with OmicShare online database. The most significant KEGG pathway was the extracellular matrix (ECM)receptor interaction (Table S3) and the pathways in cancer had the most numbers of the genes involved (Fig. 2C). Furthermore, the GO outcomes showed that the FI network mainly related to cell part (GO:0044464; cellular component), cellular process (G0:0009987; biological process), and binding (G0:0005488; molecular function) (Fig. 2D; details see in Tables S4-S6).

\section{Identification of FI network-based functional modules}

MCL was applied for the network-based module-clustering algorithm, and the absolute value of the Pearson correlation coefficient of the interacting genes was used to weigh each correlation edge. A total of six modules involving 63 genes were obtained, ranging from 7 to 19 genes per module (Table 2, Fig. 3A). Next, GO function and pathway analyses were performed on the six network-based functional modules. Through enrichment analysis (Table S7), we identified Module 0 in relation with classical protein adhesion and absorption in KEGG and integrins in Panther Pathways. Module 1 was related to JAK-STAT and JAK-STAT signaling pathway in KEGG and IFN-gamma pathway in NCI-PID. Module 2 was 
found related to ERBB signaling in KEGG and Module 3 to immunological activations in KEGG. Interleukin families in Reactome were enriched in Module 4. Meanwhile, the enrichment of GO term was also analyzed. The calculation results showed that GO functions of six modules complied with the pathway annotations (Table S8-10).

Table 1

Detailed information of the five GEO datasets in the study.

\begin{tabular}{|c|c|c|c|c|c|}
\hline Series & Organism & Study type & Platform & Country & Samples \\
\hline GSE101448 & $\begin{array}{l}\text { Homo } \\
\text { sapiens }\end{array}$ & $\begin{array}{l}\text { Expression } \\
\text { profiling } \\
\text { by array }\end{array}$ & $\begin{array}{l}\text { GPL10558IIllumina } \\
\text { HumanHT-12 V4.0 } \\
\text { expression beadchip }\end{array}$ & Germany & $\begin{array}{l}18 \text { with pancreatic } \\
\text { tumor and } 13 \text { non- } \\
\text { tumor panreatic } \\
\text { tissue samples }\end{array}$ \\
\hline GSE62165 & $\begin{array}{l}\text { Homo } \\
\text { sapiens }\end{array}$ & $\begin{array}{l}\text { Expression } \\
\text { profiling } \\
\text { by array }\end{array}$ & $\begin{array}{l}\text { GPL13667[HG-U219] } \\
\text { Affymetrix Human } \\
\text { Genome U219 Array }\end{array}$ & Belgium & $\begin{array}{l}118 \text { surgically } \\
\text { resected PDAC and } \\
13 \text { control samples }\end{array}$ \\
\hline GSE62452 & $\begin{array}{l}\text { Homo } \\
\text { sapiens }\end{array}$ & $\begin{array}{l}\text { Expression } \\
\text { profiling } \\
\text { by array }\end{array}$ & $\begin{array}{l}\text { GPL6244[HuGene- } \\
\text { 1_0-st] Affymetrix } \\
\text { Human Gene 1.0 ST } \\
\text { Array [transcript } \\
\text { (gene) version] }\end{array}$ & USA & $\begin{array}{l}69 \text { pancreatic tumors } \\
\text { and } 61 \text { adjacent non- } \\
\text { tumor tissue from } \\
\text { patients with } \\
\text { pancreatic ductal } \\
\text { adenocarcinoma }\end{array}$ \\
\hline GSE41372 & $\begin{array}{l}\text { Homo } \\
\text { sapiens }\end{array}$ & $\begin{array}{l}\text { Expression } \\
\text { profiling } \\
\text { by array }\end{array}$ & $\begin{array}{l}\text { GPL6244[HuGene- } \\
\text { 1_0-st] Affymetrix } \\
\text { Human Gene 1.0 ST } \\
\text { Array [transcript } \\
\text { (gene) version] }\end{array}$ & Italy & $\begin{array}{l}15 \text { paired pancreatic } \\
\text { tumor and adjacent } \\
\text { non-tumor tissues }\end{array}$ \\
\hline GSE28735 & $\begin{array}{l}\text { Homo } \\
\text { sapiens }\end{array}$ & $\begin{array}{l}\text { Expression } \\
\text { profiling } \\
\text { by array }\end{array}$ & $\begin{array}{l}\text { GPL6244[HuGene- } \\
\text { 1_0-st] Affymetrix } \\
\text { Human Gene 1.0 ST } \\
\text { Array [transcript } \\
\text { (gene) version] }\end{array}$ & USA & $\begin{array}{l}45 \text { matching pairs of } \\
\text { pancreatic tumor and } \\
\text { adjacent non-tumor } \\
\text { tissues from } 45 \\
\text { patients with } \\
\text { pancreatic ductal } \\
\text { adenocarcinoma }\end{array}$ \\
\hline
\end{tabular}


Table 2

Genes analyzed in six modules in FI network.

\begin{tabular}{|clll|}
\hline $\begin{array}{l}\text { Module } \\
\text { number }\end{array}$ & $\begin{array}{l}\text { Number } \\
\text { of } \\
\text { genes }\end{array}$ & $\begin{array}{l}\text { Average } \\
\text { correlation }\end{array}$ & Gene set \\
\hline 0 & 19 & 0.9927 & $\begin{array}{l}\text { ADAM28, ADAM9, CHAD, COL10A1, COL11A1, COL5A2, COL6A3, } \\
\text { COL8A1, FERMT1, ITGA11, ITGA2, ITGA3, ITGB1, ITGB4, LAMA4, } \\
\text { LUM, PLAU, SERPINH1, THBS2 }\end{array}$ \\
\hline 1 & 12 & 1.0000 & $\begin{array}{l}\text { AHR, AOX1, FCGR3A, GBP2, IFITM1, OAS1, OAS2, PRLR, RASAL2, } \\
\text { RSAD2, STAT1, TAP1 }\end{array}$ \\
\hline 3 & 9 & 0.9615 & $\begin{array}{l}\text { ADAM12, AP2B1, CTTN, EGF, IL22RA1, LIFR, NRG4, SGIP1, } \\
\text { SPRY4 }\end{array}$ \\
\hline 4 & 9 & 0.8365 & $\begin{array}{l}\text { ABLIM3, ARHGAP1, CORO1C, DAPP1, ECT2, PAK3, RAC1, RALB, } \\
\text { SEMA3A }\end{array}$ \\
\hline 5 & 7 & 0.9739 & $\begin{array}{l}\text { ANXA1, ANXA2, PLAT, S100A10, S100A4, S100A6, TNIK } \\
\text { CXCL5, FHL2, SEL1L, TFAP2A, TIMP1, TIMP2, ZNFX1 }\end{array}$ \\
\hline
\end{tabular}

Five genes common to both Module 1, with an average correlation equal to 1.00, and the set of previously selected eight genes were selected for the volcano plot analysis of the five GEO datasets (Fig. 3B, IFITM1 marker in red triangle). Combining the results from literature mining, we were interested in IFITM1 could be a potential biomarker in pancreatic cancer.

\section{Aberrant Expression of IFITM1 in pancreatic cancer}

First, we used the Oncomine database to explore the transcriptional level of IFITM1 in pancreatic cancer and normal pancreas tissues (Fig. 4D). Eight studies reported from 2003 to 2009 were filtered out with the screening condition of "IFITM1; Cancer vs. Normal Analysis; Cancer Type: Pancreatic Cancer", and assessed with a heat map analysis (Fig. 4A). Segara et al. found the level of IFITM1 in pancreatic cancer was significantly increased compared to adjacent normal pancreas samples, with a fold change of 5.521 and $P$ value of 6.78E-7[31]. The same results were also reported by Badea et al. (fold change of 3.065 and $P$ value of 8.21E-9) [32]32], Logsdon et al.(fold change of 4.104 and $P$ value of 1.14E-4) [33], Ishikawa et al.(fold change of 2.350 and $P$ value 0.008) [34] and lacobuzio-Donahue et al.( fold change of 2.855 and $P$ value of 0.005 ) [35], respectively. While Buchholz et al. and Grutzmann et al. found no significant upregulation in pancreatic cancer with $P$ value of 0.412 and $0.231[36,37]$. Recently, Pei studied in 36 pancreatic carcinoma and 16 paired normal samples, statistical significance was reported with a fold change of 2.304 and $P$ value of $0.002[38$ ]. Meanwhile, we checked the protein expression of IFITM1 with the help of the Human Protein Atlas and the positively strong level was also found in pancreatic cancer specimens compared with normal tissues (Fig. 4B, C). Furthermore, the GEPIA online tool is also used to 
validate the differential mRNA expression analysis of IFITM1 in pancreatic cancer and normal tissues (Fig. 4E).

IHC experiments were applied to validate IFITM1 expression in 90 pancreatic cancer patients. Representative IHC stained images showed that IFITM1 mainly located in the cell membrane of the pancreatic cancer tissues. A significantly up-regulated expression of IFITM1 was found in $76.7 \%$ of the patients $(69 / 90)$, which were consistent with the results analyzed by the microarray data $(P<0.001$, see in Fig. 5A-B).

\section{Correlation of IFITM1 expression with pancreatic cancer patients' clinical features}

The $\chi 2$ test was applied to assess the relations between the expressions of IFITM1 to the clinical and pathologic features of the pancreatic cancer patients, including patients' gender, age at diagnosis, tumor size, histologic differentiation, tumor stage, nodal status, distant metastasis as well as TNM stage. Histologic differentiation $(P=0.032)$ and tumor stage $(P=0.044)$ were found have close correlations with IFITM1 expression (Table 3). The significant correlation between IFITM1 and tumor stage was also verified from the GEPIA (Fig. 5C). 
Table 3

Relation between expression of IFITM1 and clinical characteristics of 90 pancreatic cancer patients

\begin{tabular}{|c|c|c|c|c|c|}
\hline \multirow[t]{2}{*}{ Parameter } & \multicolumn{2}{|l|}{ Patients } & \multicolumn{3}{|c|}{ IFITM1 expression } \\
\hline & Number & Percentage & Low & High & $P$ value \\
\hline Gender & & & & & 0.808 \\
\hline Male & 58 & 64.44 & 14 & 44 & \\
\hline Female & 32 & 35.56 & 7 & 25 & \\
\hline Age at diagnosis (year) & & & & & 0.944 \\
\hline$\leq 65$ & 54 & 60.00 & 13 & 41 & \\
\hline$>65$ & 36 & 40.00 & 9 & 27 & \\
\hline Tumor size $(\mathrm{cm})$ & & & & & 0.839 \\
\hline$\leq 4.5$ & 54 & 60.00 & 13 & 41 & \\
\hline$>4.5$ & 36 & 40.00 & 8 & 28 & \\
\hline Histologic differentiation & & & & & 0.032 \\
\hline Well & 9 & 10.00 & 4 & 5 & \\
\hline Moderate & 48 & 53.55 & 14 & 34 & \\
\hline Poor & 33 & 36.67 & 3 & 30 & \\
\hline Tumor stage & & & & & 0.044 \\
\hline 1 & 3 & 3.33 & 2 & 1 & \\
\hline 2 & 65 & 72.22 & 12 & 54 & \\
\hline 3 & 19 & 21.11 & 7 & 11 & \\
\hline 4 & 3 & 3.33 & 1 & 2 & \\
\hline Nodal status & & & & & 0.970 \\
\hline negative & 50 & 55.56 & 11 & 40 & \\
\hline 1 & 33 & 36.67 & 8 & 26 & \\
\hline 2 & 7 & 7.78 & 2 & 3 & \\
\hline Distant metastasis & & & & & 0.259 \\
\hline negative & 86 & 95.56 & 21 & 0 & \\
\hline positive & 4 & 4.44 & 65 & 4 & \\
\hline
\end{tabular}




\begin{tabular}{|llllll|}
\hline Parameter & \multicolumn{2}{c|}{ Patients } & & \multicolumn{2}{c|}{ IFITM1 expression } \\
\cline { 2 - 6 } & Number & Percentage & Low & High & Pvalue \\
\hline TNM Stage & & & & & 0.512 \\
\hline I & 3 & 3.33 & 1 & 2 & \\
\hline II & 37 & 41.11 & 6 & 31 & \\
\hline III & 42 & 46.67 & 11 & 31 & \\
\hline IV & 8 & 8.89 & 3 & 5 & \\
\hline
\end{tabular}

\section{TCGA-based analysis validates the prognostic IFITM1 signature}

A total of 184 pancreatic cancer patients in the TCGA database, with five of them had no documented T or $\mathrm{N}$ stage, leaving 179 patients for the confirmation of the relationship between IFITM1 and human pancreatic cancer. Kaplan-Meier analysis and the logrank test were used to analysis. As shown in Fig. 6A, patients with low level of IFITM1 had better disease-free survival than those with high IFITM1(Logrank $p$ $=0.036)$, and was also true for a better overall survival (Fig. 6B, Logrank $p=0.014)$.

\section{Verification of IFITM1 with prognostic signature}

For the survival analysis, the median IHC value was used as an objective cutoff to stratify 90 pancreatic cancer patients with low and high expression. We used the Kaplan-Meier analysis and the log-rank test to explore the correlation. The follow-up time was 81 months and high IFITM1 level was found significantly related to decreased overall survival $(P=0.032)$ (Fig. $6 \mathrm{C}$ ). The median overall survival of the pancreatic cancer patients with the low and high IFITM1 expression was 10.0 vs. 43.0 months, respectively

As for the univariable Cox regression analysis, positive nodal status $(P=0.008)$, TNM stage $(P=0.012)$, histologic differentiation $(P=0.004)$ and IFITM1 expression $(P=0.040)$ were significantly associated with worse outcome (Table 4). In the multivariable analysis, IFITM1 expression (HR $=2.134 ; 95 \% \mathrm{Cl} 1.073$, 4.245; $P=0.031)$ remained an independent prognostic marker for overall survival of pancreatic cancer patients (Table 4). 
Table 4

Univariable and multivariable Cox regression analyses for overall survival, accounting for IFITM1 expression and clinicopathological features in 90 pancreatic cancer patients.

\begin{tabular}{|c|c|c|c|c|}
\hline \multirow[t]{2}{*}{ Parameter } & \multicolumn{2}{|l|}{ Univariable } & \multicolumn{2}{|l|}{ Multivariable } \\
\hline & $\begin{array}{l}\text { Hazard ratio } \\
(95 \% \mathrm{Cl})\end{array}$ & $\begin{array}{l}P \\
\text { value }\end{array}$ & $\begin{array}{l}\text { Hazard ratio } \\
(95 \% \mathrm{Cl})\end{array}$ & $\begin{array}{l}P \\
\text { value }\end{array}$ \\
\hline Gender (female/male) & $\begin{array}{l}1.164(0.702, \\
1.931)\end{array}$ & 0.556 & & \\
\hline Age (years; $\leq 65 />65$ ) & $\begin{array}{l}1.200(0.733 \\
1.963)\end{array}$ & 0.469 & & \\
\hline Tumor stage $(1 / 2 / 3 / 4)$ & $\begin{array}{l}1.541(0.939 \\
2.529)\end{array}$ & 0.087 & & \\
\hline Nodal status $(0 / 1 / 2)$ & $\begin{array}{l}1.670(1.140 \\
2.447)\end{array}$ & 0.008 & $\begin{array}{l}1.026(0.535 \\
1.970)\end{array}$ & 0.938 \\
\hline Distant metastasis $(-/+)$ & $\begin{array}{l}2.548(0.921 \\
7.053)\end{array}$ & 0.072 & & \\
\hline TNM Stage(I/II/III/IV) & $\begin{array}{l}1.563(1.103, \\
2.215)\end{array}$ & 0.012 & $\begin{array}{l}1.684(0.886, \\
3.198)\end{array}$ & 0.111 \\
\hline Tumor size $(\leq 4.5 / \varangle 4.5 \mathrm{~cm})$ & $\begin{array}{l}1.212(0.739 \\
1.990)\end{array}$ & 0.446 & & \\
\hline $\begin{array}{l}\text { Histologic differentiation } \\
\text { (well/moderately/poorly) }\end{array}$ & $\begin{array}{l}1.819 \\
2.725)\end{array}$ & 0.004 & $\begin{array}{l}1.616(1.060 \\
2.462)\end{array}$ & 0.026 \\
\hline $\begin{array}{l}\text { IFITM1 expression } \\
\text { ( } \leq \text { median/>median) }\end{array}$ & $\begin{array}{l}1.971(1.030 \\
3.771)\end{array}$ & 0.040 & $\begin{array}{l}2.134(1.073 \\
4.245)\end{array}$ & 0.031 \\
\hline
\end{tabular}

\section{Immune cell infiltration of IFITM1 in pancreatic cancer patients}

IFITM1 was found involving in inflammatory processes and immune cells infiltration, which might further influence the clinical outcomes of pancreatic cancer patients. We used the TIMER database to explore a comprehensive relation between IFITM1 levels and Immune infiltrations. Positive correlations were assessed between IFITM1 and B cell (Cor $=0.171, P=2.51 \mathrm{E}-2)$, CD $4+$ T cell (Cor $=0.307, P=4.90 \mathrm{E}-5)$, macrophage (Cor $=0.204, P=7.34 \mathrm{E}-3)$, neutrophil (Cor $=0.475, P=5.20 \mathrm{E}-11)$ and dendritic cell (Cor $=$ $0.421, P=1.01 \mathrm{E}-8)$. IFITM1 level was in negative association with purity (Cor=-0.165, $P=3.1 \mathrm{E}-2)$. Only $\mathrm{CD} 8+\mathrm{T}$ cell was found having no significant relation to IFITM1 expression (Fig. 7). 


\section{IFITM1 silencing inhibits tumorigenicity of pancreatic cancer}

Three types of pancreatic cancer cell lines and normal human pancreatic duct epithelial cell line HPDE6C7 were used to examined the expressions of IFITM1. As shown in Fig. 8B-C, higher mRNA and protein levels of IFITM1 were found in BxPc-3, PanC-1 and SW1990, compared to HPDE6-C7. Two shRNA targeting IFITM1 were transfected into PanC-1 and SW1990 to detect the IFITM1 silencing effects, and the efficiency was examined both by qRT-PCR and western blot analysis (Figure D-E). We performed cell counting kit-8 assay to assess the cancer cell proliferation. Results showed that downregulation of IFITM1 significantly decreased the proliferation of PanC-1 and SW1990 cell lines(Fig. 8A). Moreover, wound-healing assay indicated that IFITM1 silencing inhibited cell migration capability and colonyformation assay showed it greatly reduced the cancer stem cell-like properties of pancreatic cancer(Fig. 8F-G).

\section{Discussion}

With the highest incidence-to-mortality ratio of solid tumors, pancreatic cancer is an elusive disease seeking for explorations to elicit the redundant mechanisms involving pathogenesis, progression and metastasis. To improve the poor clinical expectations, we identified and verified a potential molecular biomarker through network-based analytic methods of multiple datasets and etiology-based malignancies characterizing[30].

Systematically, through five microarray gene expression datasets, the FI network-based approach was used to build the functional modules for pancreatic cancer. On the basis of the diverse function of each module, the degree value and the connectivity of the nodes, IFITM1 was identified as a promising biomarker. Consistent with several bioinformatics online tools' outcomes, IFITM1 was found highly expressed in pancreatic cancer compared to normal pancreas tissues, and was confirmed through IHC experiment afterwards. Similarly, previous studies have shown high expressed IFITM1 in a variety of cancers. Through the human cancer profiling array containing 10 lung carcinoma as well as the corresponding normal samples, IFITM1 was detected increasing significantly in lung carcinoma[39]. The difference was also observed in two other studies demonstrated IFITM1 overexpression through patients' tissues and lung cancer cell lines[6,40]. Immunohistochemistry on TMA of a consecutive cohort including 174 gastroesophageal adenocarcinoma patients also detected a significant elevation of IFITM1 in primary tumors along with lymph node metastases, compared to the adjacent normal epithelium and intestinal metaplasia[41]. Gastric cancer samples derived from 27 patients and 6 gastric cancer cell lines, and 4 patients tissues and 4 tumor cells lines were assessed by Lee, S.H et al. and Y. Yang et al. separately, and showed the same findings [7, 42]. Moreover, aberrant expression of IFITM1 detected through cancer array profiling, immunohistochemistry, RT-PCR, immunoblotting and immunofluorescence analysis were verified in colorectal cancer, hepatocellular carcinoma, head and neck squamous cell carcinoma(HNSCC), gallbladder and ovarian cancer[9, 23, 43-45]. 
Notably, histologic differentiation $(P=0.032)$ and tumor stage $(P=0.044)$ of the pancreatic cancer patients were significantly correlated with IFITM1 expression in the clinical and pathological analyses. To In order to explore the underlining mechanisms, we found the role of IFITM1 have been shown in the tumorigenesis involving tumor cells unlimited proliferation, invasion, angiogenesis, metastasis and treatment resistance. Overexpression of IFITM1 was first time found enhancing cancer migration and invasion in 2005, with the cell model of gastric cancer[42]. The phenomenon was then discovered in HNSCC, glioma and gastric cells in vitro experiments and meanwhile downregulation of IFITM1 significantly decreased the activity of matrix metalloproteinase 9 (MM9)[44, 46]. Two studies revealed that depletion of IFITM1 significantly inhibited aromatase inhibitor (Al)-resistant breast cancer growth and invasion and the observation reversed when the ectopic level of IFITM1[47, 48]. Recently, Y.G. Yang et al. demonstrated IFITM1 was essentially required for the progression of non-small cell lung cancer (NSCLC) both in vitro and in vivo, and silenced expression of IFITM1 significantly reduced the capacity of sphere-formation, invasion, and migration of NSCLC[6].

To further validate the prognostic signature of IFITM1 in pancreatic cancer patients, both univariable and multivariable Cox regression analysis were assessed and the data suggested IFITM1 an independent prognostic marker. This similar prognostic values were also seen in other type of tumors[41, 43, 49]. Chemotherapy, radiation therapy and endocrine therapy are three critical and effective strategies in the cancer treatment. Accumulating evidence has indicated that IFITM1 involved in radio- and chemoresistance as well as endocrine therapy resistance. In our previous study, we explored the radiosensitive possibility of adipose-derived mesenchymal stem cells and discovered IFITM1 could be important target involving in radioresistance[23] Mechanically, upregulation level of IFITM1 was correlation to high expression of STAT3 and MMP family, also to downregulation of P53 and caspase family. The association between IFITM1 and signal transducer STAT at the molecular level was also detected and evaluated by knockdown of IFITM1 in oral tumors[50, 51]. While the interaction between IFITM1 and P53 signaling cascade, the apoptotic effects of other IFITM proteins was mainly P53-independent[52]. Yet, it is still unclear whether IFITM1 is of prime importance in the responsiveness of pancreatic cancer patients to clinical therapies.

In addition to the multiple cell functions involving anti-proliferation and adhesion, the IFITM1 is predominantly important in immune responses[53]. As we discovered above, immune cell infiltration was in significant correlations with IFITM1 in pancreatic cancer. Escape of natural killer cell recognition was reported from gastric cancer cells with increased level of IFITM1[42]. This indicated that tumors expressing high IFITM1 were insensitive to the antiproliferative therapies, might be attributed to escape from the immune surveillance.

Although we discovered the potential role of IFITM1 in pancreas cancer, limitations to this study were acknowledged. Tumor xenograft model is needed to verify the outcomes in vivo experiments, and a larger cohort of pancreatic cancer patients are expected to validate the data.

\section{Conclusion}


Taken together, our study constructed an effective FI network-based module analysis to discover the genes differently expressed between pancreatic cancer and normal pancreas tissue, and suggested that upregulation of IFITM1 is correlated to a poor clinical result of pancreatic cancer.

\section{Abbreviations}

IFN, interferon; IFITM1, IFN-induced transmembrane protein 1; ISGs, IFN-stimulated genes; GEO, Gene Expression Omnibus; DEGs, differentially expressed genes; $\mathrm{Fl}$, functional interaction; $\mathrm{GO}$, Gene Ontology; KEGG, Kyoto Encyclopedia of Genes and Genomes ; FDR, false discovery rate; TCGA, the Cancer Genome Atlas; IHC, Immunohistochemical; MCL, markov cluster algorithm.

\section{Declarations}

\section{Ethics approval and consent to participate}

The protocol of this study involving human participants was reviewed and approved by the Ethical Committees of the National Engineering Center for Biochips at Alenabio and Shanghai Outdo Biotech Company and Taizhou People's Hospitals. Informed consent was written in accordance with the Declaration of Helsinki from all participants. The use of human samples and clinical data were in accordance with the recommendations of with the Ethical Committees of the National Engineering Center for Biochips at Alenabio and Shanghai Outdo Biotech Company and Taizhou People's Hospitals.

\section{Consent for publication}

Written informed consent for publication was obtained from all participants.

\section{Availability of data and materials}

Not applicable

\section{Competing interests}

The authors declare no competing interests.

\section{Funding}

This study was supported by grants from the Chinese Medicine Research Program of Zhejiang Province (grant No.2018ZZ014) and Zhejiang Provincial key Discipline of Traditional Chinese Medicine (grant No.2017-XK-A32). 


\section{Authors' contributions}

Dr.Lingyun Wu and Dr. Xinli Zhu contributed equally to this study.

YS and MC were responsible for the research design and participated in the paper. WL and ZX drafted the manuscript, participated in data collection and analysis. WL, ZX, TM and WL performed the laboratory experiments. LT conceived the study. All authors were responsible for the data analysis and figure format.

\section{Acknowledgements}

The authors thank Professor Chen Xin (Zhejiang University School of Medicine, Hangzhou, China) for professional support and help, and Mr. Cui Jinlong (Zhejiang University School of Medicine, Hangzhou, China) for the professional assistant in tissue staining valuation.

\section{References}

1. Rahib L, Smith BD, Aizenberg R, Rosenzweig AB, Fleshman JM, Matrisian LM. Projecting cancer incidence and deaths to 2030: the unexpected burden of thyroid, liver, and pancreas cancers in the United States. Cancer Res. 2014;74:2913-21.

2. Robin F, Angenard G, Cano L, Courtin-Tanguy L, Gaignard E, Khene ZE, Bergeat D, Clement B, Boudjema K, Coulouarn C, Sulpice L. Molecular profiling of stroma highlights stratifin as a novel biomarker of poor prognosis in pancreatic ductal adenocarcinoma, $\mathrm{Br} J$ Cancer, (2020).

3. Christenson ES, Jaffee E, Azad NS. Current and emerging therapies for patients with advanced pancreatic ductal adenocarcinoma: a bright future. Lancet Oncol. 2020;21:e135-45.

4. Friedman RL, Manly SP, McMahon M, Kerr IM, Stark GR. Transcriptional and posttranscriptional regulation of interferon-induced gene expression in human cells. Cell. 1984;38:745-55.

5. Diamond MS, Farzan M. The broad-spectrum antiviral functions of IFIT and IFITM proteins. Nat Rev Immunol. 2013;13:46-57.

6. Yang YG, Koh YW, Sari IN, Jun N, Lee S, Phi LTH, Kim KS, Wijaya YT, Lee SH, Baek MJ, Jeong D, Kwon HY. Interferon-induced transmembrane protein 1-mediated EGFR/SOX2 signaling axis is essential for progression of non-small cell lung cancer. Int J Cancer. 2019;144:2020-32.

7. Lee J, Goh SH, Song N, Hwang JA, Nam S, Choi IJ, Shin A, Kim IH, Ju MH, Jeong JS, Lee YS. Overexpression of IFITM1 has clinicopathologic effects on gastric cancer and is regulated by an epigenetic mechanism. Am J Pathol. 2012;181:43-52.

8. Yu F, Xie D, Ng SS, Lum CT, Cai MY, Cheung WK, Kung HF, Lin G, Wang X, Lin MC. IFITM1 promotes the metastasis of human colorectal cancer via CAV-1. Cancer Lett. 2015;368:135-43.

9. Kim NH, Sung HY, Choi EN, Lyu D, Choi HJ, Ju W, Ahn JH. Aberrant DNA methylation in the IFITM1 promoter enhances the metastatic phenotype in an intraperitoneal xenograft model of human ovarian cancer. Oncol Rep. 2014;31:2139-46. 
10. Ramanathan A, Ramanathan A. Interferon Induced Transmembrane Protein-1 Gene Expression as a Biomarker for Early Detection of Invasive Potential of Oral Squamous Cell Carcinomas. Asian Pac J Cancer Prev. 2016;17:2297-9.

11. Sari IN, Yang YG, Phi LT, Kim H, Baek MJ, Jeong D, Kwon HY. Interferon-induced transmembrane protein 1 (IFITM1) is required for the progression of colorectal cancer. Oncotarget. 2016;7:86039-50.

12. Wright GW, Simon RM. A random variance model for detection of differential gene expression in small microarray experiments. Bioinformatics. 2003;19:2448-55.

13. Pathan M, Keerthikumar S, Ang CS, Gangoda L, Quek CY, Williamson NA, Mouradov D, Sieber OM, Simpson RJ, Salim A, Bacic A, Hill AF, Stroud DA, Ryan MT, Agbinya JI, Mariadason JM, Burgess AW, Mathivanan S, FunRich: An open access standalone functional enrichment and interaction network analysis tool, Proteomics, 15 (2015) 2597-2601.

14. Niu X, Zhang J, Ni J, Wang R, Zhang W, Sun S, Peng Y, Bai M, Zhang Z. Network pharmacology-based identification of major component of Angelica sinensis and its action mechanism for the treatment of acute myocardial infarction, Biosci Rep, 38 (2018).

15. Akey JM, Biswas S, Leek JT, Storey JD, On the design and analysis of gene expression studies in human populations, Nat Genet, 39 (2007) 807-808; author reply 808-809.

16. Croft D, O'Kelly G, Wu G, Haw R, Gillespie M, Matthews L, Caudy M, Garapati P, Gopinath G, Jassal B, Jupe S, Kalatskaya I, Mahajan S, May B, Ndegwa N, Schmidt E, Shamovsky V, Yung C, Birney E, Hermjakob H, D'Eustachio P. L. Stein, Reactome: a database of reactions, pathways and biological processes. Nucleic Acids Res. 2011;39:D691-7.

17. Shannon P, Markiel A, Ozier O, Baliga NS, Wang JT, Ramage D, Amin N, Schwikowski B, Ideker T. Cytoscape: a software environment for integrated models of biomolecular interaction networks. Genome Res. 2003;13:2498-504.

18. Wu G, Dawson E, Duong A, Haw R, Stein L. ReactomeFIViz: a Cytoscape app for pathway and network-based data analysis. F1000Res. 2014;3:146.

19. Zhao X, Xu M, Cai Z, Yuan W, Cui W, Li MD. Identification of LIFR, PIK3R1, and MMP12 as Novel Prognostic Signatures in Gallbladder Cancer Using Network-Based Module Analysis. Front Oncol. 2019;9:325.

20. Uhlen M, Fagerberg L, Hallstrom BM, Lindskog C, Oksvold P, Mardinoglu A, Sivertsson A, Kampf C, Sjostedt E, Asplund A, Olsson I, Edlund K, Lundberg E, Navani S, Szigyarto CA, Odeberg J, Djureinovic D, Takanen JO, Hober S, Alm T, Edqvist PH, Berling H, Tegel H, Mulder J, Rockberg J, Nilsson P, Schwenk JM, Hamsten M, von Feilitzen K, Forsberg M, Persson L, Johansson F, Zwahlen M, von Heijne G, Nielsen J, Ponten F, Proteomics. Tissue-based map of the human proteome, Science, 347 (2015) 1260419.

21. Rhodes DR, Yu J, Shanker K, Deshpande N, Varambally R, Ghosh D, Barrette T, Pandey A, Chinnaiyan AM. ONCOMINE: a cancer microarray database and integrated data-mining platform. Neoplasia. 2004;6:1-6. 
22. Tang Z, Li C, Kang B, Gao G, Li C, Zhang Z. GEPIA: a web server for cancer and normal gene expression profiling and interactive analyses. Nucleic Acids Res. 2017;45:W98-102.

23. Wu L, Tang Q, Yin X, Yan D, Tang M, Xin J, Pan Q, Ma C, Yan S. The Therapeutic Potential of Adipose Tissue-Derived Mesenchymal Stem Cells to Enhance Radiotherapy Effects on Hepatocellular Carcinoma. Front Cell Dev Biol. 2019;7:267.

24. Keshava Prasad TS, Goel R, Kandasamy K, Keerthikumar S, Kumar S, Mathivanan S, Telikicherla D, Raju R, Shafreen B, Venugopal A, Balakrishnan L, Marimuthu A, Banerjee S, Somanathan DS, Sebastian A, Rani S, Ray S, Harrys Kishore CJ, Kanth S, Ahmed M, Kashyap MK, Mohmood R, Ramachandra YL, Krishna V, Rahiman BA, Mohan S, Ranganathan P, Ramabadran S, Chaerkady R. A. Pandey, Human Protein Reference Database-2009 update. Nucleic Acids Res. 2009;37:D767-72.

25. Chatr-Aryamontri A, Breitkreutz BJ, Oughtred R, Boucher L, Heinicke S, Chen D, Stark C, Breitkreutz A, Kolas N, O'Donnell L, Reguly T, Nixon J, Ramage L, Winter A, Sellam A, Chang C, Hirschman J, Theesfeld C, Rust J, Livstone MS, Dolinski K, Tyers M. The BioGRID interaction database: 2015 update. Nucleic Acids Res. 2015;43:D470-8.

26. Brown KR, Jurisica I. Unequal evolutionary conservation of human protein interactions in interologous networks. Genome Biol. 2007;8:R95.

27. Orchard S, Ammari M, Aranda B, Breuza L, Briganti L, Broackes-Carter F, Campbell NH, Chavali G, Chen C, del-Toro N, Duesbury M, Dumousseau M, Galeota E, Hinz U, lannuccelli M, Jagannathan S, Jimenez R, Khadake J, Lagreid A, Licata L, Lovering RC, Meldal B, Melidoni AN, Milagros M, Peluso D, Perfetto L, Porras P, Raghunath A, Ricard-Blum S, Roechert B, Stutz A, Tognolli M, van Roey K, Cesareni G, Hermjakob $\mathrm{H}$. The MIntAct project-IntAct as a common curation platform for 11 molecular interaction databases. Nucleic Acids Res. 2014;42:D358-63.

28. Licata L, Briganti L, Peluso D, Perfetto L, lannuccelli M, Galeota E, Sacco F, Palma A, Nardozza AP, Santonico E, Castagnoli L, Cesareni G. MINT, the molecular interaction database: 2012 update. Nucleic Acids Res. 2012;40:D857-61.

29. Salwinski L, Miller CS, Smith AJ, Pettit FK, Bowie JU, Eisenberg D. The Database of Interacting Proteins: 2004 update. Nucleic Acids Res. 2004;32:D449-51.

30. Wu G, Feng X, Stein L. A human functional protein interaction network and its application to cancer data analysis. Genome Biol. 2010;11:R53.

31. Segara D, Biankin AV, Kench JG, Langusch CC, Dawson AC, Skalicky DA, Gotley DC, Coleman MJ, Sutherland RL, Henshall SM. Expression of HOXB2, a retinoic acid signaling target in pancreatic cancer and pancreatic intraepithelial neoplasia. Clin Cancer Res. 2005;11:3587-96.

32. Badea L, Herlea V, Dima SO, Dumitrascu T, Popescu I. Combined gene expression analysis of wholetissue and microdissected pancreatic ductal adenocarcinoma identifies genes specifically overexpressed in tumor epithelia. Hepatogastroenterology. 2008;55:2016-27.

33. Logsdon CD, Simeone DM, Binkley C, Arumugam T, Greenson JK, Giordano TJ, Misek DE, Kuick R, Hanash S. Molecular profiling of pancreatic adenocarcinoma and chronic pancreatitis identifies multiple genes differentially regulated in pancreatic cancer. Cancer Res. 2003;63:2649-57. 
34. Ishikawa M, Yoshida K, Yamashita Y, Ota J, Takada S, Kisanuki H, Koinuma K, Choi YL, Kaneda R, Iwao T, Tamada K, Sugano K, Mano H. Experimental trial for diagnosis of pancreatic ductal carcinoma based on gene expression profiles of pancreatic ductal cells. Cancer Sci. 2005;96:38793.

35. lacobuzio-Donahue CA, Maitra A, Olsen M, Lowe AW, van Heek NT, Rosty C, Walter K, Sato N, Parker A, Ashfaq R, Jaffee E, Ryu B, Jones J, Eshleman JR, Yeo CJ, Cameron JL, Kern SE, Hruban RH, Brown $\mathrm{PO}$, Goggins $\mathrm{M}$. Exploration of global gene expression patterns in pancreatic adenocarcinoma using cDNA microarrays. Am J Pathol. 2003;162:1151-62.

36. Buchholz M, Braun M, Heidenblut A, Kestler HA, Kloppel G, Schmiegel W, Hahn SA, Luttges J, Gress TM. Transcriptome analysis of microdissected pancreatic intraepithelial neoplastic lesions. Oncogene. 2005;24:6626-36.

37. Grutzmann R, Pilarsky C, Ammerpohl O, Luttges J, Bohme A, Sipos B, Foerder M, Alldinger I, Jahnke B, Schackert HK, Kalthoff H, Kremer B, Kloppel G, Saeger HD. Gene expression profiling of microdissected pancreatic ductal carcinomas using high-density DNA microarrays. Neoplasia. 2004;6:611-22.

38. Pei H, Li L, Fridley BL, Jenkins GD, Kalari KR, Lingle W, Petersen G, Lou Z, Wang L. FKBP51 affects cancer cell response to chemotherapy by negatively regulating Akt. Cancer Cell. 2009;16:259-66.

39. Andreu P, Colnot S, Godard C, Laurent-Puig P, Lamarque D, Kahn A, Perret C, Romagnolo B. Identification of the IFITM family as a new molecular marker in human colorectal tumors. Cancer Res. 2006;66:1949-55.

40. Yan J, Jiang Y, Lu J, Wu J, Zhang M, Inhibiting of Proliferation, Migration, and Invasion in Lung Cancer Induced by Silencing Interferon-Induced Transmembrane Protein 1 (IFITM1), Biomed Res Int, 2019 (2019) 9085435.

41. Borg D, Hedner C, Gaber A, Nodin B, Fristedt R, Jirstrom K, Eberhard J, Johnsson A. Expression of IFITM1 as a prognostic biomarker in resected gastric and esophageal adenocarcinoma. Biomark Res. 2016;4:10.

42. Yang Y, Lee JH, Kim KY, Song HK, Kim JK, Yoon SR, Cho D, Song KS, Lee YH, Choi I. The interferoninducible 9-27 gene modulates the susceptibility to natural killer cells and the invasiveness of gastric cancer cells. Cancer Lett. 2005;221:191-200.

43. He J, Li J, Feng W, Chen L, Yang K. Prognostic significance of INF-induced transmembrane protein 1 in colorectal cancer. Int J Clin Exp Pathol. 2015;8:16007-13.

44. Hatano H, Kudo Y, Ogawa I, Tsunematsu T, Kikuchi A, Abiko Y, Takata T. IFN-induced transmembrane protein 1 promotes invasion at early stage of head and neck cancer progression. Clin Cancer Res. 2008;14:6097-105.

45. Li D, Yang Z, Liu Z, Zou Q, Yuan Y. DDR2 and IFITM1 Are Prognostic Markers in Gallbladder Squamous Cell/Adenosquamous Carcinomas and Adenocarcinomas. Pathol Oncol Res. 2019;25:157-67. 
46. Gonzalez-Avila G, Sommer B, Mendoza-Posada DA, Ramos C, Garcia-Hernandez AA, Falfan-Valencia R. Matrix metalloproteinases participation in the metastatic process and their diagnostic and therapeutic applications in cancer. Crit Rev Oncol Hematol. 2019;137:57-83.

47. Choi HJ, Lui A, Ogony J, Jan R, Sims PJ, Lewis-Wambi J. Targeting interferon response genes sensitizes aromatase inhibitor resistant breast cancer cells to estrogen-induced cell death. Breast Cancer Res. 2015;17:6.

48. Lui AJ, Geanes ES, Ogony J, Behbod F, Marquess J, Valdez K, Jewell W, Tawfik O, Lewis-Wambi J. IFITM1 suppression blocks proliferation and invasion of aromatase inhibitor-resistant breast cancer in vivo by JAK/STAT-mediated induction of p21. Cancer Lett. 2017;399:29-43.

49. Balbous A, Cortes U, Guilloteau K, Villalva C, Flamant S, Gaillard A, Milin S, Wager M, Sorel N, Guilhot J, Bennaceur-Griscelli A, Turhan A, Chomel JC, Karayan-Tapon L, A mesenchymal glioma stem cell profile is related to clinical outcome, Oncogenesis, 3 (2014) e91.

50. Yang J, Li L, Xi Y, Sun R, Wang H, Ren Y, Zhao L, Wang X, Li X. Combination of IFITM1 knockdown and radiotherapy inhibits the growth of oral cancer. Cancer Sci. 2018;109:3115-28.

51. Liang R, Li X, Zhu X, Deciphering the Roles of IFITM1 in Tumors, Mol Diagn Ther, (2020).

52. Xu Y, Yang G, Hu G. Binding of IFITM1 enhances the inhibiting effect of caveolin-1 on ERK activation. Acta Biochim Biophys Sin (Shanghai). 2009;41:488-94.

53. Siegrist F, Ebeling M, Certa U. The small interferon-induced transmembrane genes and proteins. $J$ Interferon Cytokine Res. 2011;31:183-97.

\section{Figures}



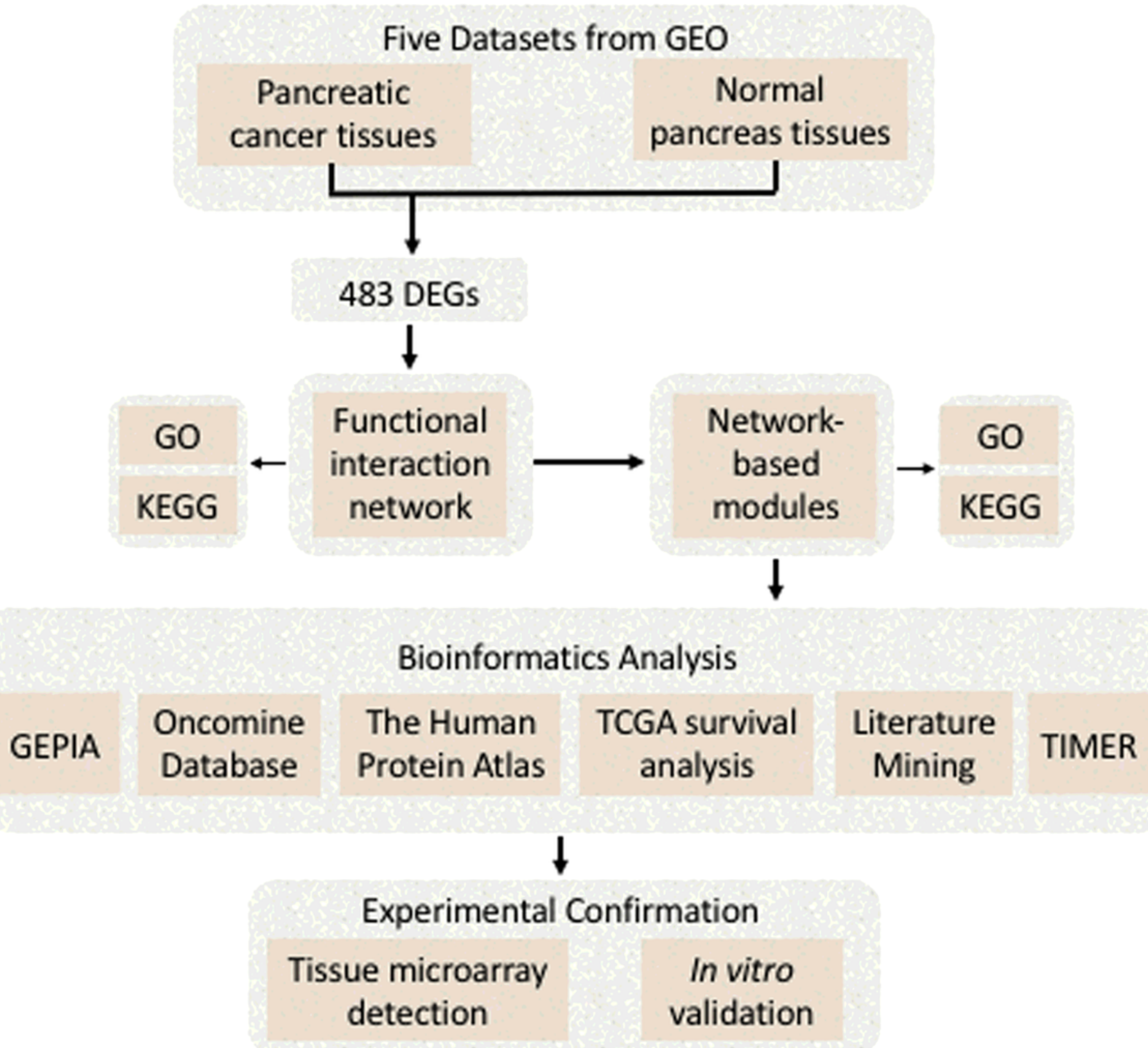

Figure 1

A detailed flowchart of identifying and verifying the targeted DEGs associated with pancreatic cancer. 
A
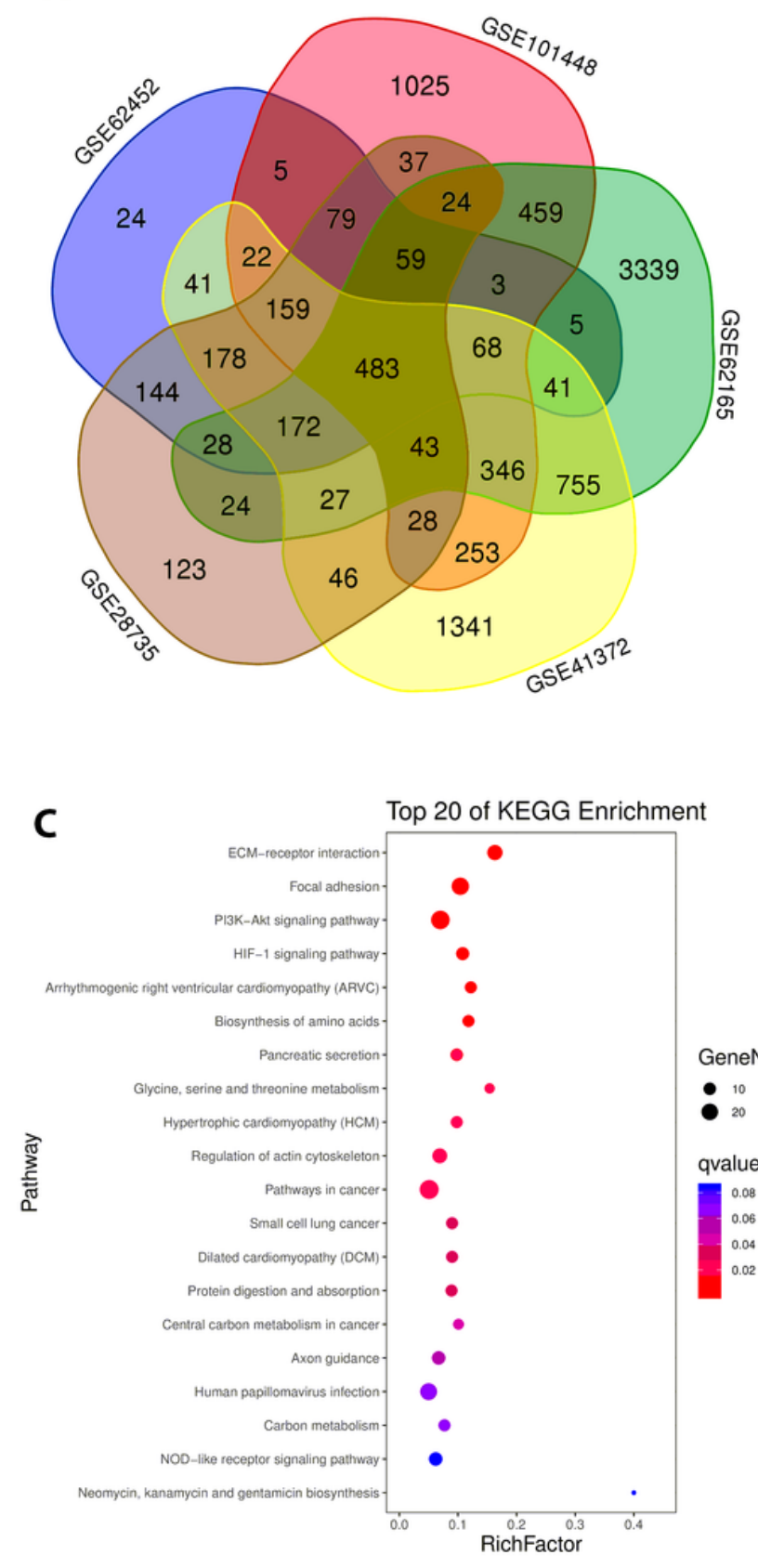

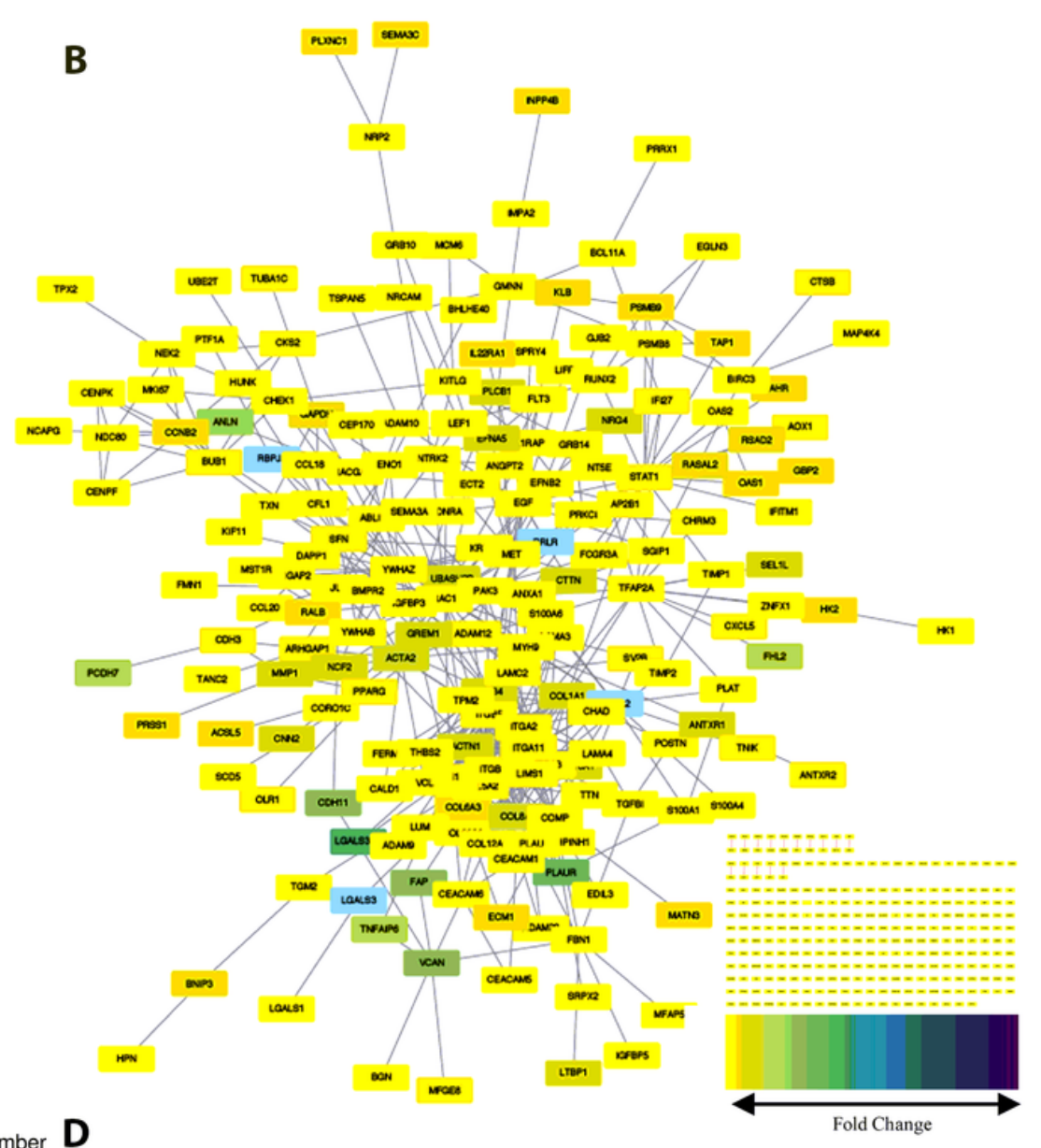

D

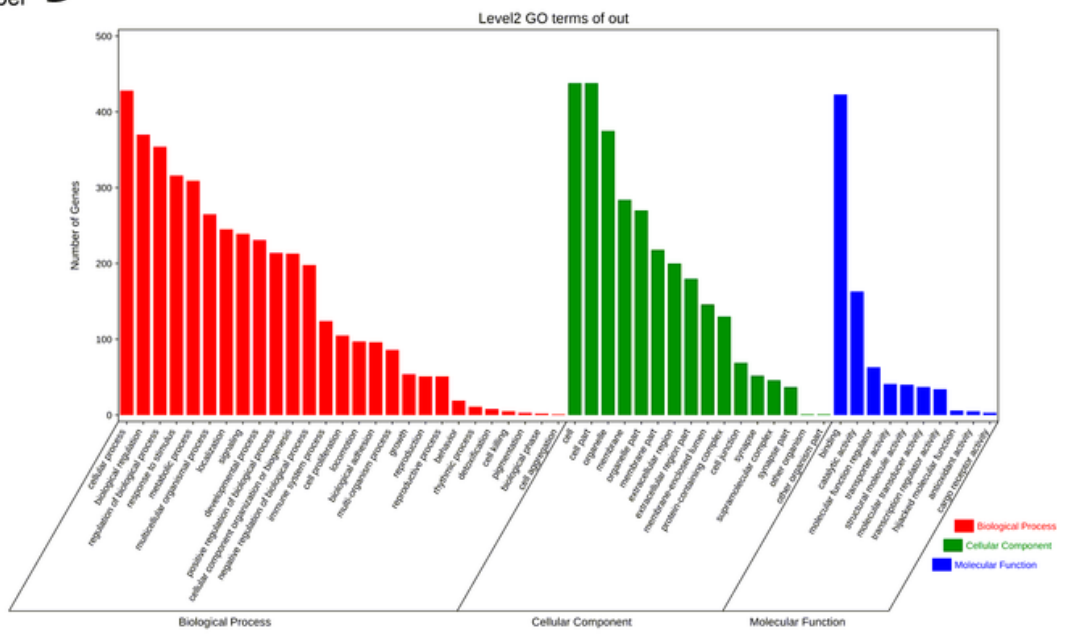

\section{Figure 2}

Screening of the DEGs in the pancreatic cancer establishment of the FI network. A. A flower-shaped venn diagram showing 483 genes differentially expressed between pancreatic cancer and normal pancreas tissues among 5 studies. B. The FI network was established using pancreatic cancer-related 483 differentially expressed genes. Edges were based upon $\mathrm{FI}$ annotation. Node sizes represented the degree values of the FI network and the node colors defined fold changes in pancreatic cancer-related DEGs, ranging from yellow for low expression to purple for high expression, compared to non-cancerous 
samples. C-D. Gene functional enrichment of the 483 differentially expressed DEGs. KEGG showed the top 20 signaling pathways and GO analysis showed the biological processes and molecular functions involved in differential genes.

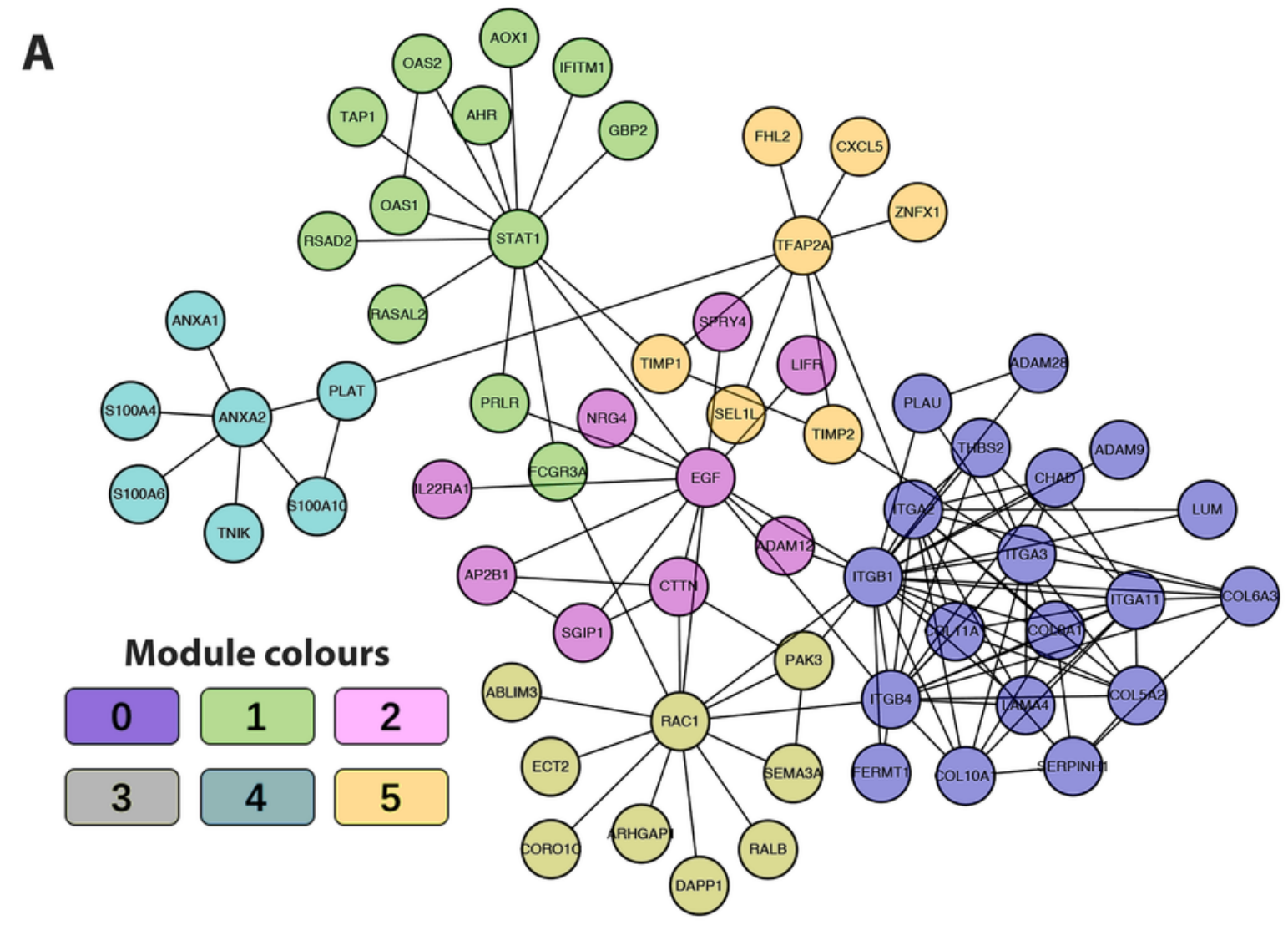

B

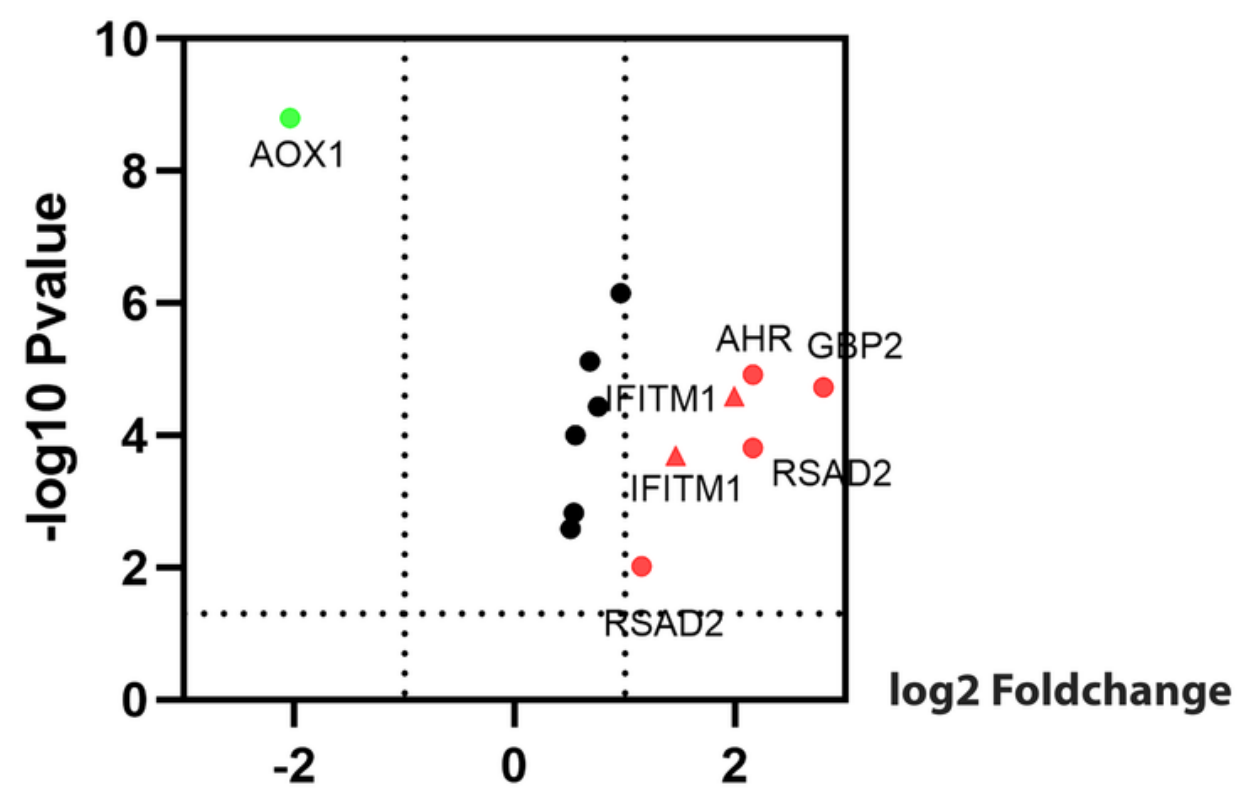

Figure 3

Construction of FI network-based module genes. A. Functional-network constructed by six FI basedmodules comprise 23 genes in different colors. B. Volcano map show differentiating pancreatic cancer 
samples from normal samples, with red representing significantly upregulated genes, green representing significantly downregulated genes, and the red triangle representing IFITM1.

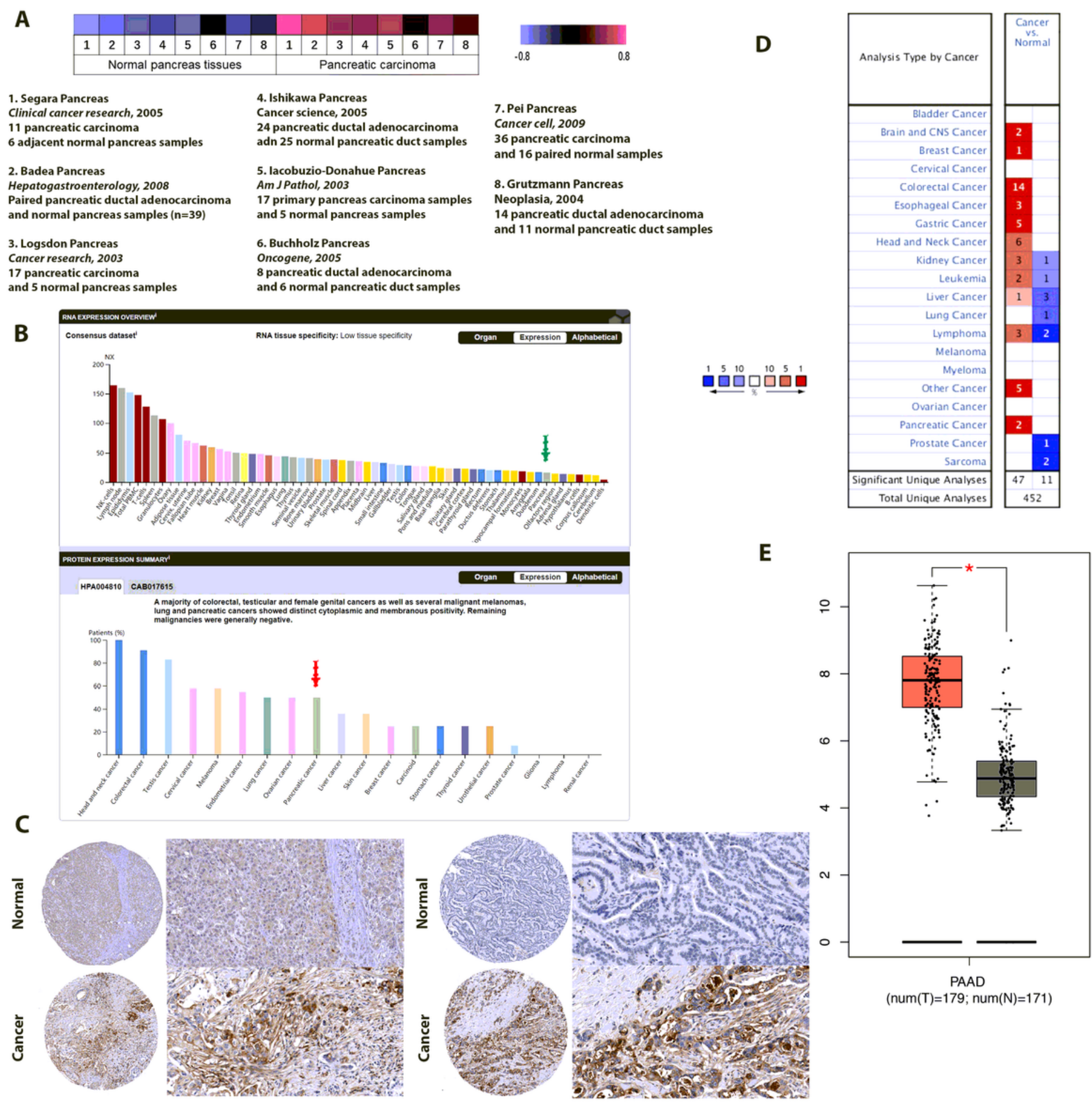

\section{Figure 4}

The expression of IFITM1 between pancreatic cancer and normal pancreas samples. A. Heat map of IFITM1 associated with pancreatic cancer among eight studies. B-C. Immunohistochemical analysis of IFITM1 expression in pancreatic cancer and normal pancreas tissue and an overview of IFITM1 levels in pancreatic tumors and normal pancreas tissues. Data were derived from the Human Protein Atlas 
database. The green and the red arrows were pointing cancer and normal tissue, respectively. (top: Protein levels of IFITM1 in normal tissue (staining: negative; intensity: negative; quantity: none); botton: Protein levels of IFITM1 in pancreatic cancer tissue (staining: high; intensity: strong; quantity: > 75\%). D. mRNA levels of IFITM1 in 20 types of cancers vs. normal tissues. The figure represented the number of datasets involving statistically significant upregulated as well as downregulated expression of IFITM1. E. The box plot showing the expression profile of the IFITM1 based on GEPIA. The red node represented pancreatic cancer, gray node represented normal samples. ${ }^{*} \mathrm{P}<0.05$.

\section{A \\ Tumor( $\times 20)$}

HE

IFITM1
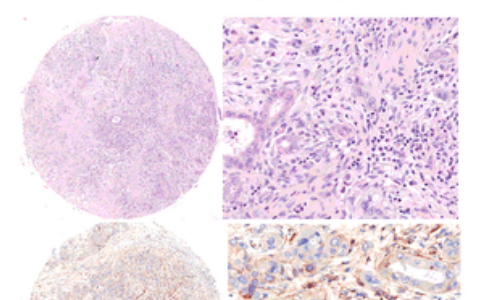

HE

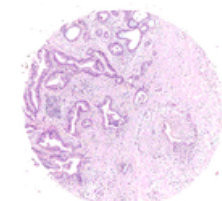

IFITM1
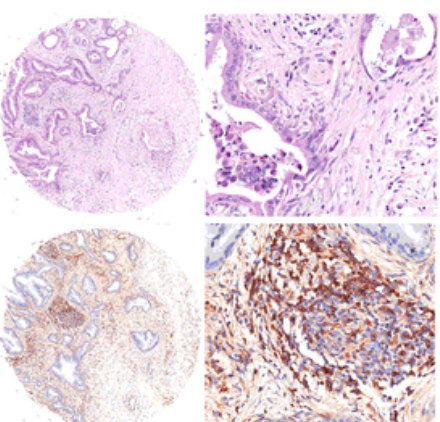

HE

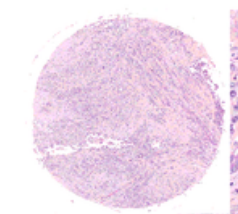

IFITM1
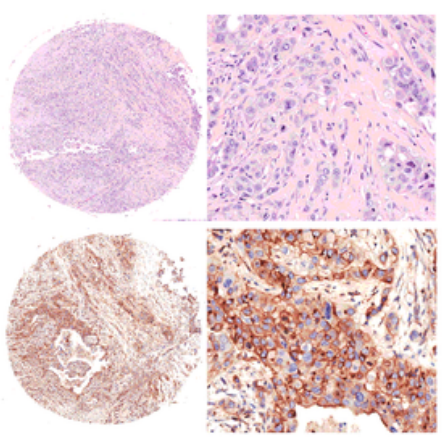

HE
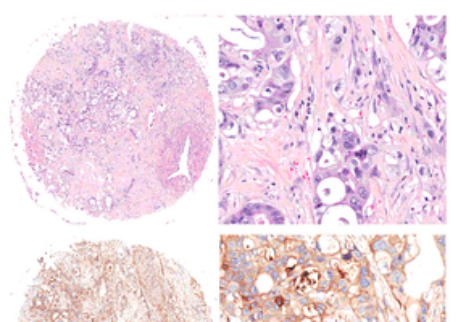

IFITM1

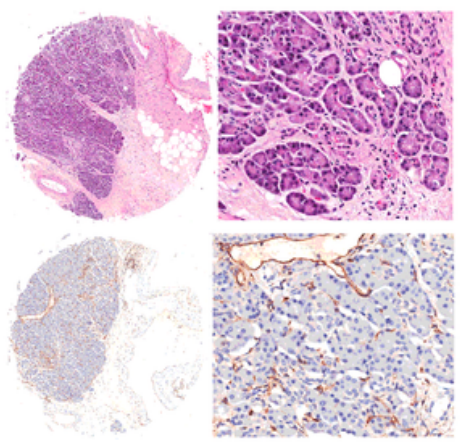

\section{Peritumor $(\times 20)$}
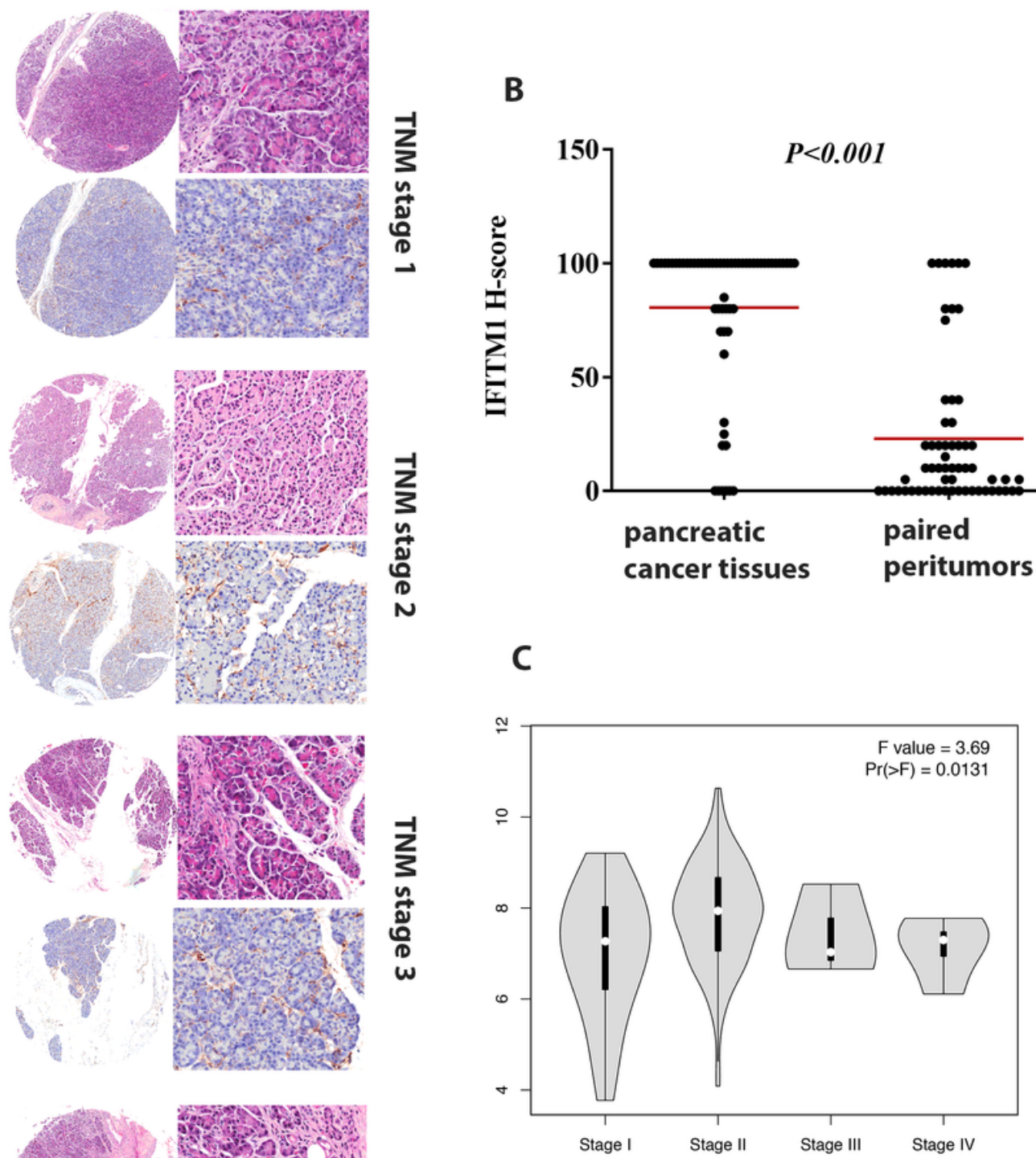

Figure 5 
IFITM1 expressions in pancreatic cancer samples and paired peritumor tissues. A. IFITM1 in representative cases of pancreatic cancer tissues in TNM stage 1-4 were detected by immunohistochemical experiments, respectively. Original magnification $\times 20$. B. The differential protein expression of IFITM1 was shown in pancreatic cancer tissues and matched non-tumor tissues of 90 patients as indicated. The median extents of the expressions were indicated by the horizontal line in the scatterplot figure. C. Correlations between different expressed IFITM1 and the pathological TNM stage of pancreatic cancer patients. ${ }^{*} \mathrm{P}<0.05$
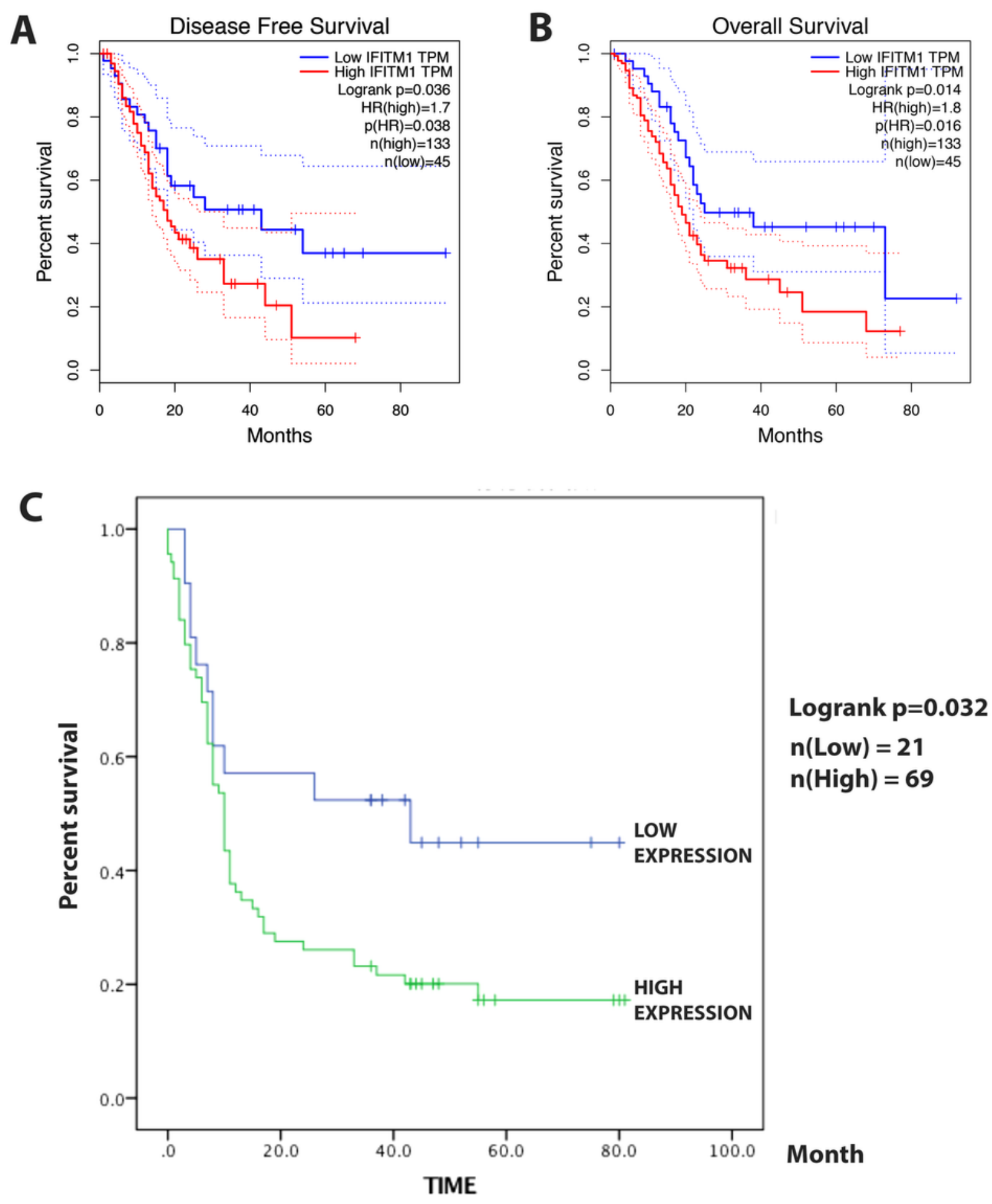
Figure 6

The prognostic value of different expressed IFITM1 in pancreatic cancer patients. A. Kaplan-Meier curve for the disease-free survival of pancreatic cancer patients with low vs. high expression of IFITM1 (median PFS less than 20 months vs. more than 20 months, respectively; log-rank test, $P=0.036$ ). B. Kaplan-Meier curve for the overall survival (OS) of patients with low vs. high expression of IFITM1 (log-rank test, $P=$ 0.016). C. Kaplan-Meier curve for the 90 pancreatic cancer patients in our study
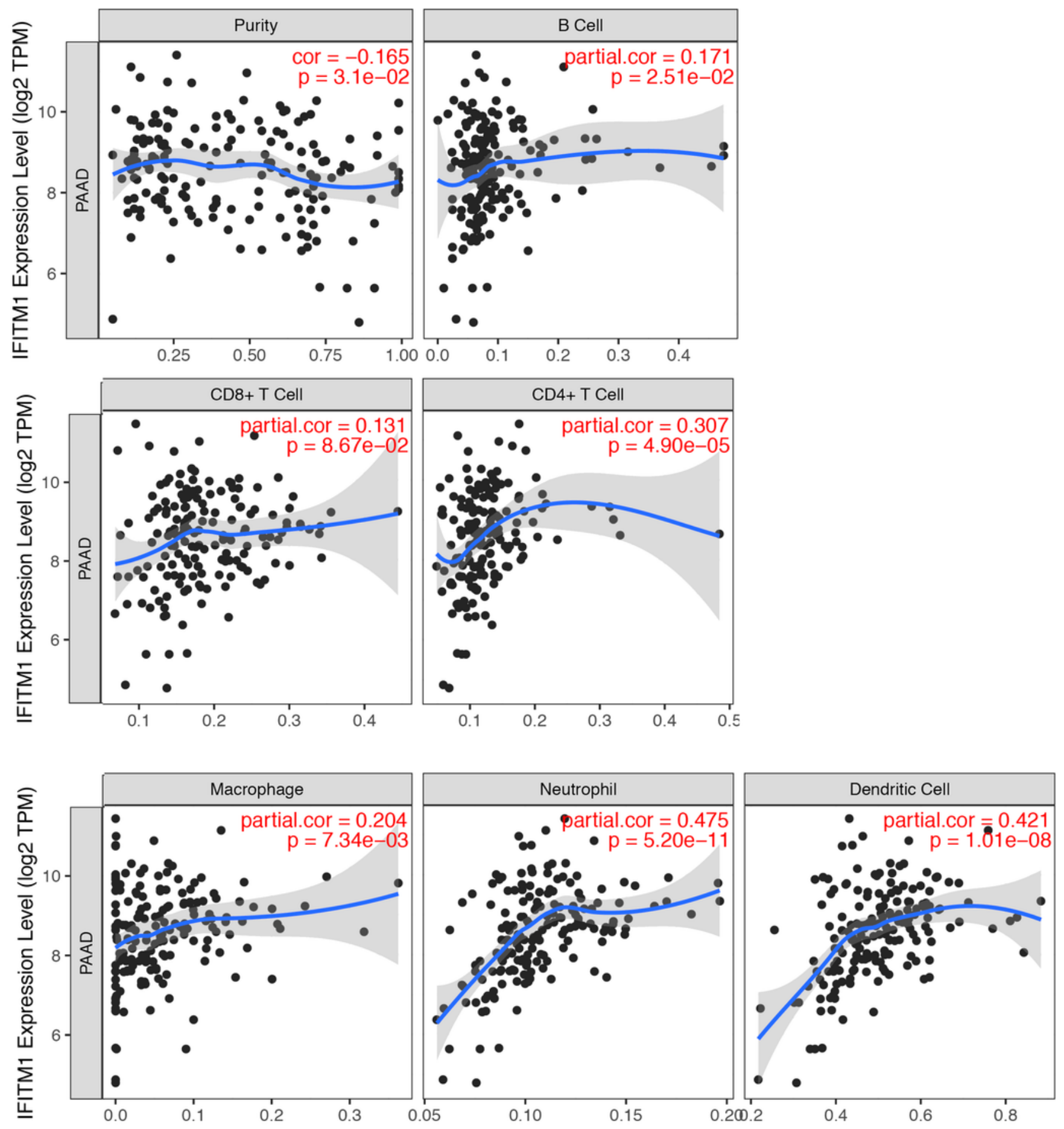

Infiltration Level 
Figure 7

The correlations between different IFITM1 expression and the immune cell infiltration (TIMER) in pancreatic cancer.

A

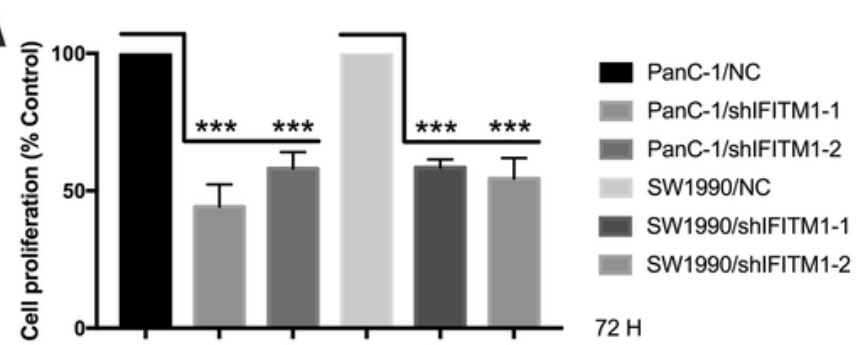

C

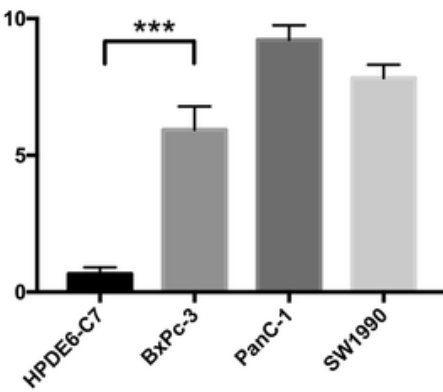

D

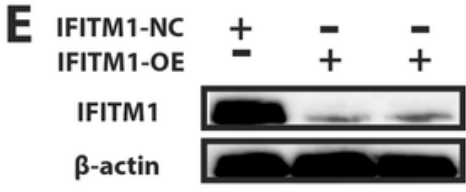

PanC-1

G

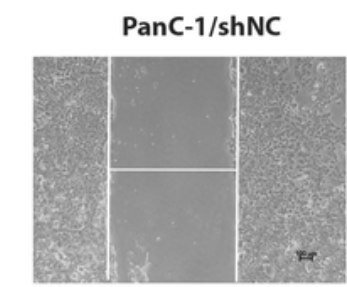

$6 \mathrm{H}$

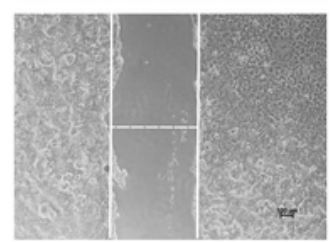

$12 \mathrm{H}$

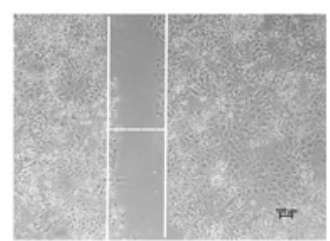

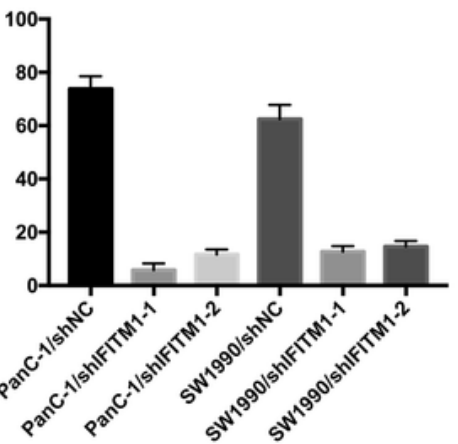
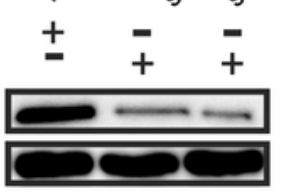

SW1990

PanC-1/shIFITM1-1
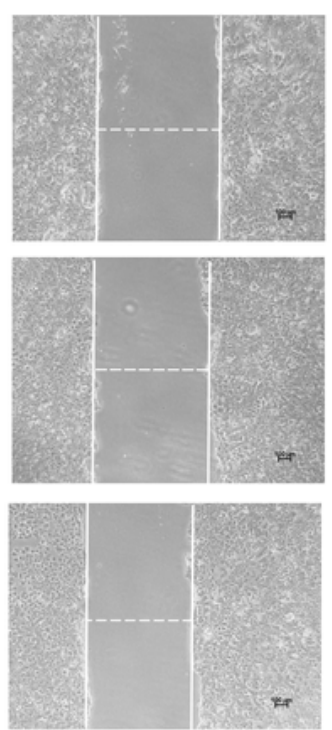

B

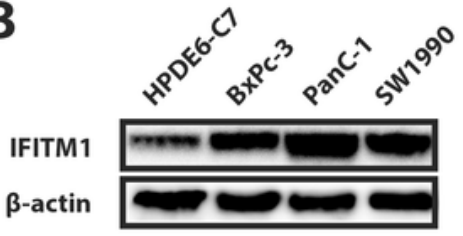

$\mathbf{F}$
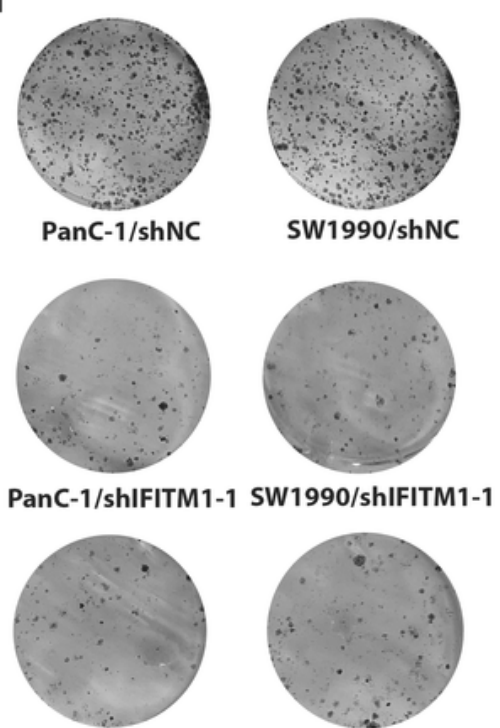

PanC-1/shIFITM1-2 SW1990/shIFITM1-2

PanC-1/shIFITM1-2
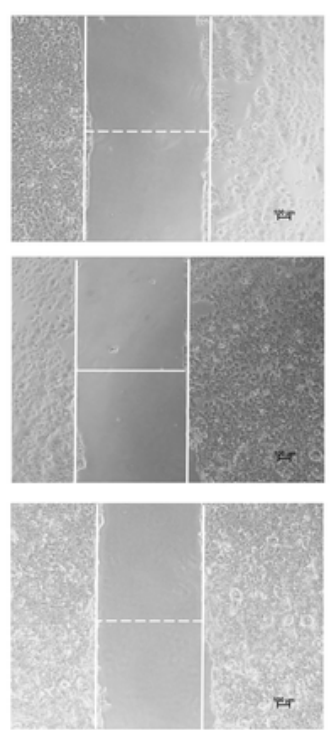

Figure 8 
Depletion of IFITM1 decreased the tumorigenicity of pancreatic cancer cells. A. Control (shNC) or IFITM1depleted (shIFITM1-1 and shIFITM1-2) of PanC-1 and SW1990 cell lines were incubated for 72 hours to determine the cell proliferation rate by cell counting kit-8 assay. Data represent the means $\pm S D$ of three independent experiments $(* * * \mathrm{P}<0.001)$. B-C. Detection of IFITM1 mRNA expression in three different pancreatic cancer cell lines as well as HPDE6-C7 by qRT-PCR and western blot analysis. GAPDH and $\beta-$ Actin were used as controls, respectively. The results were expressed as the means $\pm S D$ of three independent experiments $(* * * P<0.001)$. D-E. Pancreatic cancer cell lines were transfected with shRNAs (shIFITM1-1 and shIFITM1-2), and the expression level of IFITM1 was assessed by qRT-PCR and western blot analysis using GAPDH and $\beta$-Actin as controls, respectively. The results are expressed as means $\pm S D$ of three independent experiments. F. Colony-formation assay was performed to show decreased cancer stem cell-like properties of PanC-1 and SW1990 cells transfected with shIFITM1-1 or shIFITM1-2 compared with control in vitro. G. The wound-healing assay was performed to assess the effect of IFITM1 silencing on the wound closure ability of PanC-1 cells. Representative images were shown (magnification 100x).

\section{Supplementary Files}

This is a list of supplementary files associated with this preprint. Click to download.

- Supplementarytables.xlsx

- Supplementarytables.xlsx 